\title{
Multiscale network modeling of oligodendrocytes reveals molecular components of myelin dysregulation in Alzheimer's disease
}

Andrew T. McKenzie ${ }^{1,2,3}$, Sarah Moyon ${ }^{4,13}$, Minghui Wang ${ }^{1,2}$, Igor Katsyv ${ }^{1,2,3}$, Won-Min Song ${ }^{1,2}$, Xianxiao Zhou ${ }^{1,2}$, Eric B. Dammer ${ }^{5}$, Duc M. Duong ${ }^{6,7}$, Joshua Aaker ${ }^{8}$, Yongzhong Zhao ${ }^{1,2}$, Noam Beckmann ${ }^{1,2}$, Pei Wang ${ }^{1,2}$, Jun Zhu',2, James J. Lah ${ }^{9,10}$, Nicholas T. Seyfried ${ }^{6,7,9}$, Allan I. Levey ${ }^{9,10}$, Pavel Katsel ${ }^{11}$, Vahram Haroutunian 2,11,12, Eric E. Schadt ${ }^{1,2}$, Brian Popko ${ }^{8}$, Patrizia Casaccia $2,4,13^{*}$ and Bin Zhang ${ }^{1,2^{*}}$

\begin{abstract}
Background: Oligodendrocytes (OLs) and myelin are critical for normal brain function and have been implicated in neurodegeneration. Several lines of evidence including neuroimaging and neuropathological data suggest that Alzheimer's disease (AD) may be associated with dysmyelination and a breakdown of OL-axon communication.

Methods: In order to understand this phenomenon on a molecular level, we systematically interrogated OLenriched gene networks constructed from large-scale genomic, transcriptomic and proteomic data obtained from human AD postmortem brain samples. We then validated these networks using gene expression datasets generated from mice with ablation of major gene expression nodes identified in our AD-dysregulated networks.

Results: The robust $\mathrm{OL}$ gene coexpression networks that we identified were highly enriched for genes associated with $A D$ risk variants, such as BIN1 and demonstrated strong dysregulation in AD. We further corroborated the structure of the corresponding gene causal networks using datasets generated from the brain of mice with ablation of key network drivers, such as UGT8, CNP and PLP1, which were identified from human AD brain data. Further, we found that mice with genetic ablations of $\mathrm{Cnp}$ mimicked aspects of myelin and mitochondrial gene expression dysregulation seen in brain samples from patients with AD, including decreased protein expression of BIN1 and GOT2.
\end{abstract}

Conclusions: This study provides a molecular blueprint of the dysregulation of gene expression networks of OL in $A D$ and identifies key OL- and myelination-related genes and networks that are highly associated with AD.

Keywords: Alzheimer's disease, Oligodendrocyte, Myelin, co-expression network, Causal network, RNA sequencing, Proteomics, Differential expression, CNP, BIN1

\footnotetext{
*Correspondence: Patrizia.Casaccia@mssm.edu;

patrizia.casaccia@asrc.cuny.edu; bin.zhang@mssm.edu

Sarah Moyon, Patrizia Casaccia and Bin Zhang are Co-senior authors. Andrew T. McKenzie and Sarah Moyon contributed equally to this work.

${ }^{2}$ Icahn Institute of Genomics and Multiscale Biology, Icahn School of Medicine at Mount Sinai, One Gustave L. Levy Place, New York, NY 10029, USA

${ }^{1}$ Department of Genetics and Genomic Sciences, Icahn School of Medicine at Mount Sinai, One Gustave L. Levy Place, 1470 Madison Avenue, Room S8-111, New York, NY 10029, USA

Full list of author information is available at the end of the article
} 


\section{Background}

Alzheimer's disease (AD) causes a progressive dementia that affects approximately $1 / 6$ th of people in the US age 75 and above [1]. Although the number one risk factor for $\mathrm{AD}$ is advanced age, the reason for this remains unknown [2, 3]. A wealth of evidence has emerged over the past decade to support the role of non-neuronal cells, especially astrocytes and microglia, in amyloid beta $(A \beta)$ processing and $\mathrm{AD}$ pathogenesis [4-6]. While less well studied, several lines of evidence have suggested that dysregulation of oligodendrocytes (OLs) and associated dysmyelination might be important in AD pathology. For example, human neuroimaging studies have shown that white matter changes occur early in $\mathrm{AD}$ and are predictive of disease status [7-9]. In particular, MRI studies have detected white matter volume atrophy in multiple brain regions prior to changes in gray matter in AD progression [10-12]. Further, post-mortem human pathological studies have demonstrated that the pattern of neurofibrillary tangle deposition in AD is highly correlated with the developmental pattern of myelination, with late-myelinated axonal tracts substantially more vulnerable to degeneration in $\mathrm{AD}[13,14]$. Recent reports have highlighted the importance of OLs and myelin metabolic function for axonal health and transport capacity [15-20], thereby suggesting the possibility that OL-driven axonal damage could precede a secondary demyelination in the pathogenesis of $\mathrm{AD}$. In particular, there are several mouse models of ablation of the OLassociated myelin genes Ugt8 [21], Cnp [22, 23], and Plp1 [24, 25], in which axonal degeneration occurs in the presence of minimal ultrastructural myelin alterations and therefore are well suited to study altered OL gene expression, presumably leading to myeling dysfunction preceding the onset of neurodegeneration. To investigate the hypothesis that $\mathrm{OL}$ dysregulation in $\mathrm{AD}$ may be part of the underlying mechanism leading to neurodegeneration, we sought to employ a detailed molecular and systems-level analysis to provide a molecular substrate for the potential role of OLs in mediating the initial axonal damage.

In this study, we systematically examined and validated OL-enriched gene networks to uncover key genes and molecular signaling circuits of OLs in AD. We built upon AD-associated and OL-enriched networks constructed in a previous study of genetic, gene expression, and pathophysiologic data in late-onset AD [26]. We constructed a union of the three OL-enriched modules from a multi-tissue $\mathrm{AD}$ co-expression network and found that it was strongly enriched for AD risk factor genes. Our OL-enriched consensus module includes genes encoding proteins associated with $\mathrm{A} \beta$-production PSEN1 and BACE1, as well as the AD risk factor genes BIN1, PSEN1, PICALM, and UNC5C [27-30]. We next built co-expression networks from a large-scale proteomics data set, identifying a strong loss of coordination among proteins in the most OL-enriched network, an interaction of this dysregulation and dementia status, as well as a down-regulation of key OL network genes, including BIN1. We then used the OL modules to construct regulatory networks and found that the topological structures of our OL-enriched networks were validated through in vitro and in vivo perturbations of the predicted key regulatory genes in the networks. Further, transcriptomic analysis of brain tissue isolated from mice with a genetic ablation of three top key driver genes (Ugt8, Cnp, and Plp1) recapitulated key aspects of the dysregulation in gene pathways related to myelination that are seen in human AD brains. We chose to profile the mice with these genetic ablations at an early stage of development (postnatal day 20), in order to detect alterations in gene pathways occurring during the process of myelination and prior to the onset of widespread axon degeneration in Cnp-KO [22] or Plp1-KO [24] mice. This approach allowed us to define alterations in OL gene expression occurring during the "pre-symptomatic" or prodromal phase of the disease, as opposed to reactive changes that might be consequent to axonal degeneration. We found that differentially expressed gene (DEG) signature in the Cnp knockout (KO) mouse mimicked gene expression changes detected in $\mathrm{AD}$ brains at the early stages of the pathology, both at the gene pathway and individual protein level, thereby suggesting that dysregulation of OLs in general and CNP in particular may play a key role in driving $\mathrm{AD}$-associated gene expression changes.

\section{Methods}

\section{Oligodendrocyte network construction from AD data and} key driver analysis

We re-analyzed data from the Harvard Brain Tissue Resource Center (HBTRC) consisting of 376 late-onset Alzheimer's disease brain samples as well as 173 nondemented brain samples, harvested from the cerebellum (CBM), dorsolateral prefrontal cortex (Brodmann area 9; henceforth, PFC), and visual cortex (Brodmann area 7; $\mathrm{VC}$ ), which has been previously described [26] (GEO: GSE44772). Based upon the HBTRC AD data, we previously built up a multi-tissue weighted gene coexpression network using WGCNA [26, 31]. In order to find the $\mathrm{AD}$ OL-specific modules, we tested the enrichment of each module for the gene signatures specifically expressed in OLs. To do this, we employed datasets on cell enrichment and identified the genes most highly expressed in myelinating OLs compared to the non-OL cell types [32]. Three modules, one with probes primarily derived from each of the three investigated brain regions were found to be the most enriched for the OL 
gene signature. We therefore refer to these as the "region-specific oligodendrocyte co-expression network" modules. We further inferred an interaction network for each OL-enriched and region-specific gene module by integrating gene expression and DNA genotypic data, as previously described [26]. Specifically, relationships between genes in each co-expression module were inferred based on conditional independence tests of gene expression in a Bayesian framework, and the presence of more expression single nucleotide polymorphisms (eSNPs) associated with a gene were used as priors to break Markov equivalence [33]. We refer to each of these networks as the "region-specific OL-enriched Bayesian interaction networks". For robustness, we combined the genes in the three region-specific co-expression networks into a core OL gene set (COLGS), merged the three brain region-specific Bayesian interaction networks by a set union of directed links into a core OL-enriched Bayesian interaction network (COLBN). The gene symbols from this previous study were updated to current Hugo Gene Nomenclature Committee (HGNC) standards using the $\mathrm{R}$ package HGCNhelper (v. 0.3.1), and the two gene symbols in the OL-enriched networks that were still mapped to multiple symbols were mapped to the more common symbol (MARCH1 and LPAR1) for legibility. In order to identify key regulatory genes in this interaction network, we then performed key driver analysis on COLBN [34, 35], which uses network connectivity to infer regulatory importance scores for genes.

\section{Enrichment of brain co-expression modules in AD GWAS risk factor genes}

In order to find the enrichment of COLGS and other co-expression modules in Alzheimer's risk factor genes, we converted the International Genomics of Alzheimer's Project (IGAP) GWAS SNP-level data set [28] to genelevel $p$-value calls using VEGAS2 [36], and used the genes with significant association at a nominal $p<0.05$ for further analysis. We then measured the enrichment of this 543 AD GWAS risk factor gene set in the 62 overall qualifying multiscale $\mathrm{AD}$ modules with at least 50 genes using Fisher's Exact Test (FET).

\section{Proteomics data analysis from PFC human postmortem brain samples}

Grey matter brain samples in $50 \mathrm{mg}$ aliquots were harvested from the prefrontal cortex (PFC; Brodmann Area 10) from the autopsied brains of persons with a wide range of cognitive status at the time of death, ranging from no cognitive impairment to dementia, as well as a wide range of Braak scores, from 0 to 6 . Liquid chromatography-tandem mass spectrometry (LC-MS/ MS) was used to measure the abundance of peptides in each brain sample, from which a protein-level quantitation was estimated using MaxQuant (v1.5.3.30). We used WGCNA to define modules of proteins in the proteomics data, with a soft-thresholding power coefficient of 3. We next annotated these modules based on their relative FET enrichment in the human homologues of genes specifically expressed in each of the five major mouse brain cell types (see "Estimating brain cell type enrichment").

Within this OL-enriched module, we performed modular differential connectivity analysis in order to assess the overall difference in between samples classified as non-AD (Braak 0-2) and AD (Braak 5-6), calculated using the mean difference in z-scores option in DGCA [37] (v. 1.0.1), with 10,000 permutation samples to assess significance. We used a Student's t-test to measure differences in average expression between conditions, using the $q$ value $R$ package [38] to estimate false discovery rates in the context of the multiple hypothesis tests.

\section{Generating in vivo mouse genetic perturbation signatures Animals}

Use of animals in this research was strictly compliant with the guidelines set forth by the US Public Health Service in their policy on Humane Care and Use of Laboratory Animals, and in the Guide for the Care and Use of Laboratory Animals. All animal procedures received prior approval from the Institutional Animal Care and Use Committee at Icahn School of Medicine at Mount Sinai.

\section{Tissue collection}

For each of the control and knockout model mice of the three key drivers (Cnp, Ugt8, and Plp1), mice of either sex were sacrificed at postnatal day 20 and tissue was flash-frozen in liquid nitrogen vapors. The frontal cortex and cerebellum were dissected on ice and immediately processed for RNA isolation. Integrity of the RNA was confirmed by measuring RNA Integrity Number (RIN) and only samples with RIN > 8.5 were used for RNA sequencing.

\section{RNA isolation and reverse transcription}

RNA was isolated using Trizol reagent (Invitrogen, CA) and cleaned using RNeasy Mini kit (Qiagen, CA). Ribosomal RNA was removed from the samples using RiboZero rRNA Removal Kit (Illumina, CA). Approximately 500 nanograms of total RNA was used in cDNA library construction with the TruSeq RNA Sample Prep Kit (Illumina, CA), followed by RNA sequencing using an Illumina HiSeq2000.

\section{Read mapping and quantification of RNAseq data}

RNA-sequencing reads were mapped to the mouse genome (mm10, UCSC assembly) using Bowtie (version 
2.2.3.0), TopHat (version 2.0.11), and SamTools (version 0.1.19.0) using a read length of 100. For RNAseq knockout experiments, reads were converted to counts at the gene level using HTSeq [39] on the BAM files from TopHat2 using the UCSC known genes data set. For each key driver knockout and brain region, genes that mapped less than 100 counts in $80 \%$ or more of the samples were filtered out from downstream analysis, because these genes are likely to have especially high variance in expression calls.

\section{Compartmental approach to compare of mouse key driver perturbation signatures with human postmortem $A D$ gene expression signatures}

We found the enrichment of both mouse key driver knockout DEG signatures, aggregated across significant DEGs $(p<0.05$, FDR $<0.3)$ from both the frontal cortex and cerebellum, as well as two human $\mathrm{AD}$ gene expression signatures in the gene ontology pathways. The prefrontal cortex (PFC) human AD DEG signature was estimated from the HBTRC cohort. We used the list of genes identified as previously identified as having significantly different RNA levels in brain samples from persons with high levels of Alzheimer's neuropathology (Braak $=5-6)$ compared brain samples from persons with low levels of Alzheimer's neuropathology (Braak $=0-2)$ via a Student's ttest [26]. The second human AD DEG signature is from a previous study that identified genes with a significant trend in RNA expression changes across the severity spectrum of $\mathrm{AD}$ (control, incipient, moderate, and severe) in the hippocampus (HIPP) [40]. In this data set, we selected the genes as having an increasing or decreasing trend in expression across AD severity stages and an ANOVA $p$-value $<0.05$ as the HIPP AD DEG signature. We used the moduleGO function in DGCA [37] (version 1.0.1) to perform gene ontology (GO) enrichment analysis on these DEG sets, which leverages the GOstats (version 2.34) [41] and org.Hs.eg.db GO annotation (version 3.1.2) $\mathrm{R}$ packages. We filtered for those $\mathrm{GO}$ terms with less than 800 and greater than 100 gene symbols. We adjusted the enrichment $p$-values for all GO terms in each DEG set using the Benjamani-Hochberg method. In order to determine whether there was a similar pattern of dysregulation in the mouse key driver knockout models as in human $\mathrm{AD}$, we next found the degree to which the compartment overlaps intersected, using the $\mathrm{R}$ package SuperExactTest (version 0.99.2) [42].

\section{In vivo validation of gene expression Animals}

The Cnp-cre knock-in mouse line has been described previously [23]. For the sake of clarity, in this manuscript, $\mathrm{Cnp}^{+/+}$mice are called $\mathrm{Cnp}$-WT and $\mathrm{Cnp} p^{\text {cre/cre }}$ mice are called Cnp-KO.

\section{Western blot}

Mice of either sex were sacrificed at postnatal day 60 and brains were cut into $1 \mathrm{~mm}$ coronal sections using a refrigerated brain matrix. Corpus callosum (CC) was dissected from coronal sections on ice using a light microscope. The tissue was then immediately processed for protein extraction. Protein lysates $(50 \mu \mathrm{g})$ were separated by sodium dodecyl sulfate-polyacrylamide gel electrophoresis (SDS-PAGE) and transferred onto a PolyVinylidene DiFluoride (PVDF) (Millipore, Billerica, MA, USA) membrane using a buffer containing $25 \mathrm{mM}$ Tris base, $\mathrm{pH}$ 8.3, $192 \mathrm{mM}$ glycine, 20\% (vol/vol) methanol for $1 \mathrm{~h}$ at $100 \mathrm{~V}$ at $4{ }^{\circ} \mathrm{C}$. Membranes were blocked for $1 \mathrm{~h}$ in $10 \%$ Milk/0.1\% Tween/TBS, then incubated overnight at $4{ }^{\circ} \mathrm{C}$ with the primary antibody diluted 1:1000 in 5\% BSA/ $0.02 \%$ sodium azide $/ 0.1 \%$ Tween/TBS. Antibodies used are: mouse anti-CNPase (Sternberger Inc., SMI-91, 1:5,00), mouse anti-alpha-TUBULIN (Calbiochem, CP06, 1:5000), rabbit anti-BIN1 (Abcam, ab185950, 1:2500), rabbit anti-GOT2 (Abcam, ab171739, 1:2500). After rinsing with $0.1 \%$ Tween/TBS, membranes were incubated $2 \mathrm{~h}$ at room temperature with the secondary light-chain specific antibody (Jackson Immunoresearch, 1:10,000) in 10\% Milk/0.1\% Tween/TBS. After rinsing, membranes were incubated with ECL (Amersham) for $3 \mathrm{~min}$ and then revealed. Quantification was carried out on three biological and technical replicates per genotype, using ImageJ. Protein expressions were normalized to alpha-TUBULIN expression, then compared to their respective expression levels in Cnp-WT samples.

\section{Immunohistochemistry}

Mice were perfused with $4 \%$ paraformaldehyde and post-fixed overnight in the same solution at $4{ }^{\circ} \mathrm{C}$. Tissue samples were then transferred to $70 \%$ ethanol, sequentially dehydrated and embedded in paraffin. Fourmicrometer sections were cut, deparaffinized and rehydrated. Antigen retrieval was performed by incubating slides in sub-boiling $\left(94{ }^{\circ} \mathrm{C}\right)$ citrate buffer $(\mathrm{pH}$ 6.0) for 15 min. Slides were incubated in blocking buffer $(20 \%$ Normal Goat Serum / 1\% BSA / PBS 1X) for $1 \mathrm{~h}$ at room temperature and then incubated overnight at $4{ }^{\circ} \mathrm{C}$ with the primary antibodies in 1\% BSA / PBS 1X. Antibodies used are: mouse anti-OLIG2 (Millipore, MABN50, 1:200), mouse anti-NeuN (Millipore, MAB377, 1:200), mouse anti-GFAP (Sternberger Inc., SMI-22, 1:200), rabbit anti-BIN1 (Abcam, ab185950, 1:200), rabbit anti-GOT2 (Abcam, ab171739, 1:200). After rinsing with Tris-buffer / $2 \%$ milk, sections were processed with he appropriate Alexa Fluor conjugated secondary antibodies (1:1000 in 1\% BSA / PBS 1X, Invitrogen), washed with Tris-buffer, and mounted using Fluoromount-G with DAPI. All images were acquired using a Zeiss Observer A1 fluorescent microscope or 
Zeiss LSM780 upright Confocal. Quantification was carried out on two-three sections per mouse and three-four mice for each genotype evaluated using ImageJ.

\section{Results}

A robust myelination- and oligodendrocyte-enriched gene module is strongly associated with genetic data in lateonset $A D$

The primary goal of this study was to interrogate OLenriched multiscale gene networks constructed from human AD postmortem brain samples (Fig. 1). We first identified co-expressed human gene modules, that were built from data obtained from three regions [e.g. prefrontal cortex (PFC), visual cortex (VC), and cerebellum (CBM)] from postmortem late-onset $\mathrm{AD}$ human brains samples from a large cohort of patients [26]. We further annotated these gene modules with additional gene sets to investigate their associations with OLs and AD. We then constructed Bayesian gene regulatory networks for the OLenriched co-expression modules, identified key regulatory genes in the regulatory networks, and systematically validated the topological structures of the regulatory networks based on a series of gene perturbation experiments in vitro and in vivo. Specifically, in order to identify OL coexpression networks in AD, we tested each of the 62 coexpression modules with at least 50 genes for the enrichment of genes expressed specifically in each of five major brain cell types, i.e., astrocytes, endothelial cells, microglia, neurons, and myelinating OLs [32] (Fig. 2). We identified three co-expression modules with the strongest enrichment of OL genes (Fig. 2), which we subsequently combined, leading to a set of 1631 unique gene symbols,

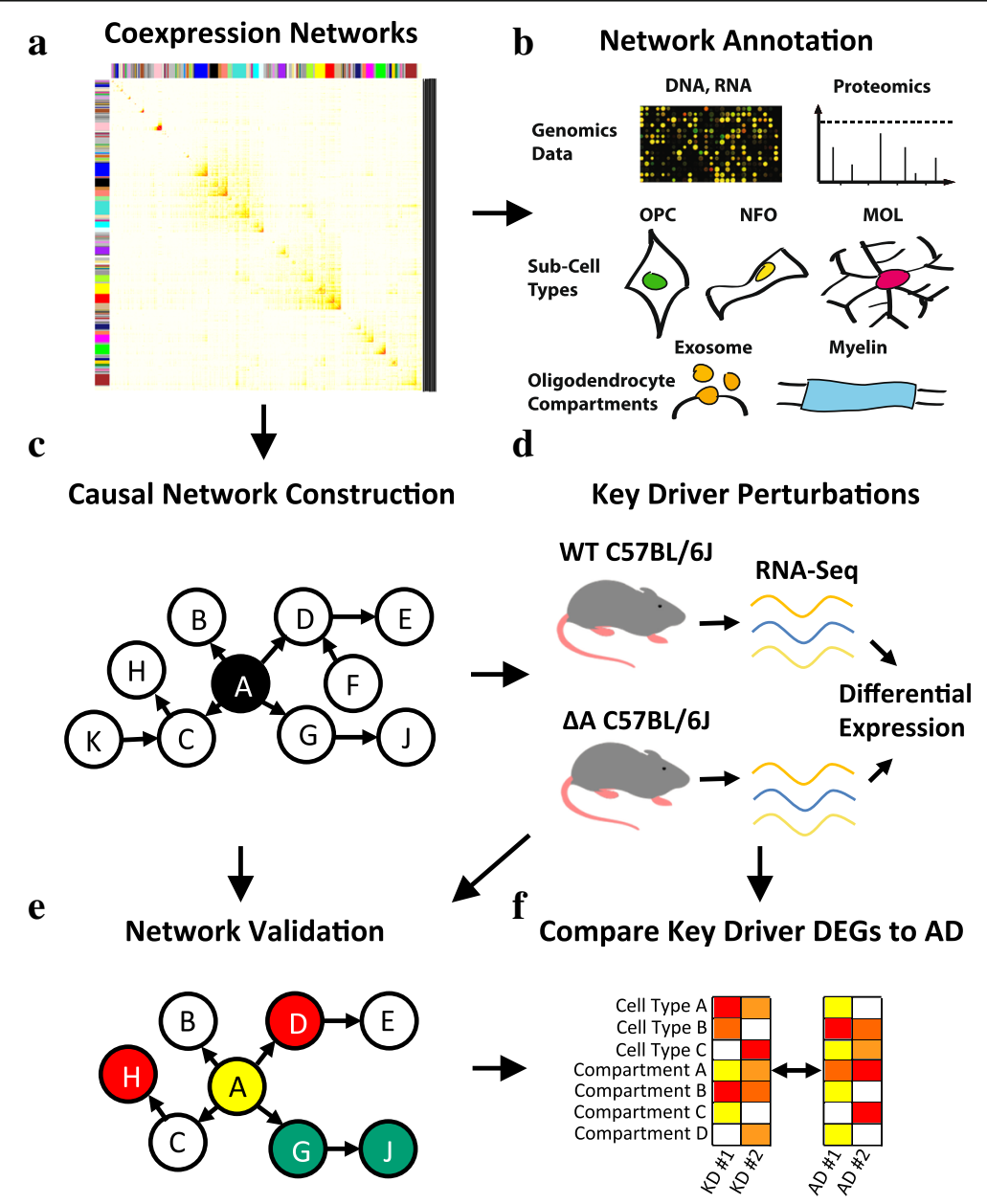

Fig. 1 Workflow of the analyses performed in this study. Human postmortem AD brain tissue samples from multiple brain regions were used to construct coexpression networks (a) using Weighted Gene Coexpression Network Analysis (WGCNA). The oligodendrocyte/myelination enriched coexpressed gene modules from WGCNA were annotated by a variety of external data sets including DNA, RNA, proteomic, cell type, and proteome compartment data (b). Next, Bayesian gene regulatory networks were constructed based on the DNA and RNA postmortem human AD data (c). The Bayesian networks were used to identify key driver genes and several key drivers were perturbed in mouse models to identify their downstream targets (d). The gene signatures in response to the perturbations of the key driver genes were used to validate the network structure (e) and to compare with the differential expression patterns in human AD postmortem brains (f) 


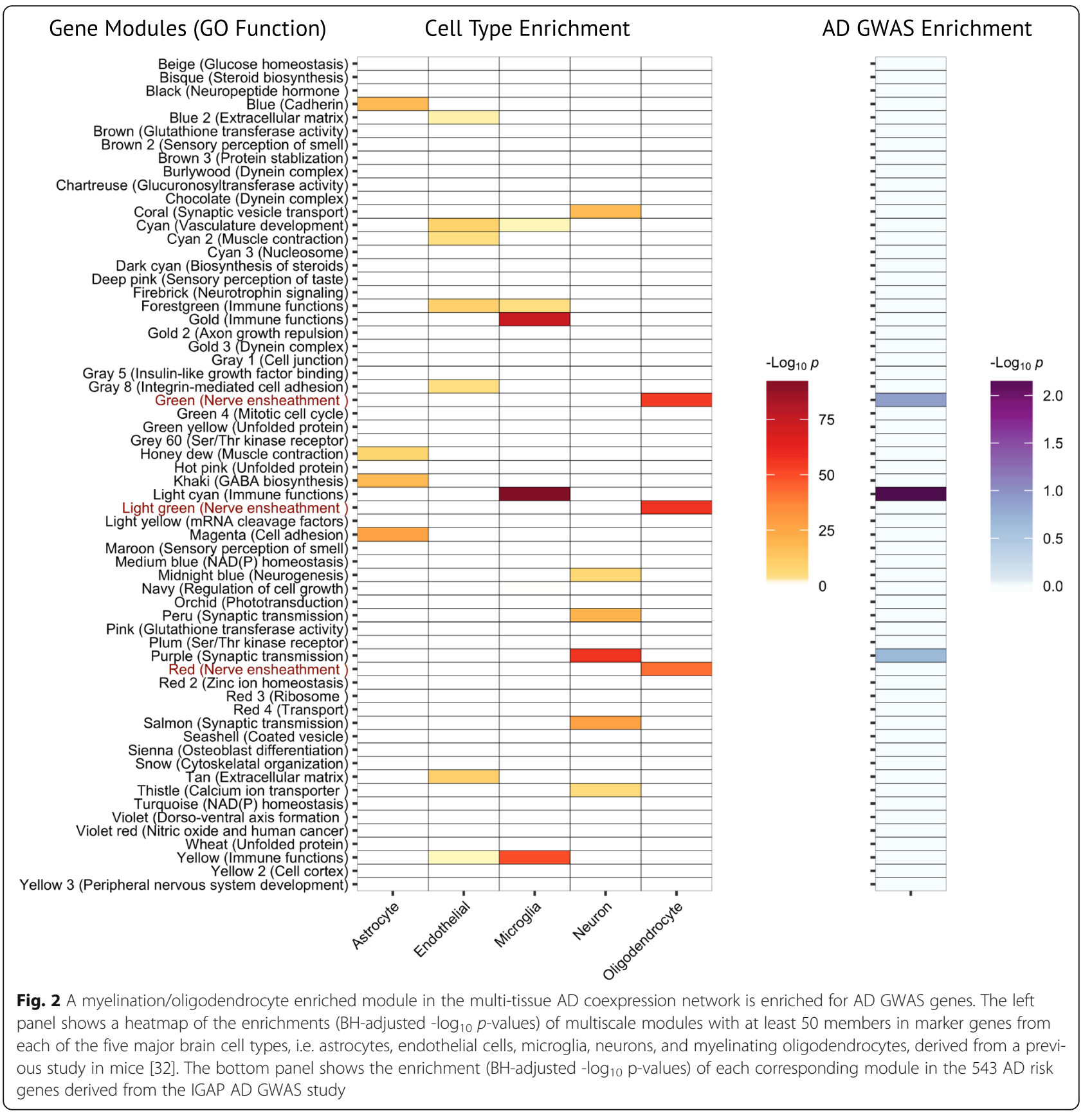

which we henceforth refer to as the core oligodendrocyte gene set (COLGS). Notably, because the three OLenriched co-expression modules were each primarily identified in one of the three brain regions from the multitissue experiment, by combining them we sought to obtain a more sensitive measure of genes whose expression is associated with OLs in the context of AD across brain regions. COLGS is highly enriched for genes encoding proteins identified in the myelin proteome [43] (Fold Enrichment $(\mathrm{FE})=1.92$, Fisher's Exact Test $(\mathrm{FET}) p=2.4 \mathrm{e}-$ $15)$, and is also enriched for genes specifically expressed in each of oligodendrocyte precursor cells $(\mathrm{FE}=2.8$, $p=4.2 \mathrm{e}-17$ ), newly formed oligodendrocytes $(\mathrm{FE}=6.2$, $p=1.0 \mathrm{e}-84)$, and myelinating oligodendrocytes [32] ( $\mathrm{FE}=7.4, p=2.5 \mathrm{e}-87$ ), indicating that genes in COLGS capture a wide spectrum of OL functions.

To systematically evaluate the AD genetics of COLGS, we identified 543 genes with nominally significant $(p<0.05)$ gene-level associations with $\mathrm{AD}$ based on a meta-analysis of AD genome-wide association study (GWAS) data by the International Genomics of Alzheimer's Project (IGAP) [28]. We identified a significant enrichment 
of the $\mathrm{AD}$ risk genes in COLGS $(\mathrm{FE}=1.71, p$ value $=0.0004)$, due to the presence of BIN1, PICALM, $N M E 8, S N X 1$, and other genes. Of all the individual coexpression modules, one OL-enriched module had the second strongest enrichment for AD GWAS risk genes, second only to an immune- and microglia-enriched module (Fig. 2, Table 1). We further highlighted the specific genes in COLGS that were also identified as AD risk genes (Fig. 3, Table 2). These results suggest that the COLGS contains a relatively large proportion of $\mathrm{AD}$ risk genes.

Next, we sought to examine the robustness of COLGS to a variety of sources of variance. We first used data from an independent study that also identified coexpression modules in human AD postmortem brain RNA expression samples [44]. Despite originating from a different brain region (the hippocampus), we found that $83 \%$ of the genes in the module with the strongest OL-enrichment in this data set overlapped with the members of COLGS $(\mathrm{FE}=18.3$, $p=9.1 \mathrm{e}-79)$. In order to measure the robustness of the co-expression network with respect to an alternative gene expression modality, we utilized a large AD proteomic data set from the prefrontal cortex (PFC;
Brodmann area 10), which we corrected for batch, age of death, and sex. We used WGCNA [31] to identify gene modules in this proteomic data set, and found that the module with the strongest OLenrichment ( $\mathrm{FE}=1.7, p=0.0053)$, has $50 \%$ overlap with COLGS ( $\mathrm{FE}=10.7, p=6.6 \mathrm{e}-58$ ), including the $\mathrm{AD}$ risk factor BIN1 (Additional file 1: Figure S1, Additional file 2). These results suggest a robust coregulation of the COLGS genes at both the transcript and protein levels in $\mathrm{AD}$.

\section{Dysregulation of an oligodendrocyte-associated module in $A D$ at the protein level}

Our previous analysis showed that the three OL-enriched modules were each among the modules with the strongest loss of connectivity in AD samples on the RNA expression level [26]. We sought to extend these results by interrogating gene expression dysregulation in the OL-enriched proteomics module, which includes 150 proteins and is the most OL-enriched module. We found that this module has a significant decrease in correlation in AD samples (mean difference in z-transformed correlation $=-0.466$, empirical $p$-value $=0.0489$; Fig. $4 \mathrm{a})$, thus validating the

Table 1 The region-specific oligodendrocyte-enriched gene networks are among the top associated functional coexpression modules with the 543 significant Alzheimer's disease GWAS hits

\begin{tabular}{|c|c|c|c|c|c|c|}
\hline Module Name & Enriched Cell Type & Enriched GO Term & Size & Shared & P-Value & $\begin{array}{l}\text { Adjusted } \\
\text { P-Value }\end{array}$ \\
\hline Light cyan & Microglia & Immune functions & 559 & 23 & $1.91 \mathrm{e}-05$ & 0.00118 \\
\hline Green & Oligodendrocyte & Nerve ensheathment & 1098 & 32 & 0.000389 & 0.0121 \\
\hline Purple & Neuron & Synaptic transmission & 847 & 26 & 0.000636 & 0.0131 \\
\hline Gold & Microglia & Immune functions & 400 & 14 & 0.00352 & 0.0546 \\
\hline Salmon & Neuron & Synaptic transmission & 750 & 21 & 0.00582 & 0.0722 \\
\hline Burlywood & Ependymal Cell & Dynein complex & 114 & 6 & 0.008 & 0.0806 \\
\hline Magenta & Astrocyte & Cell adhesion & 841 & 22 & 0.0103 & 0.0806 \\
\hline Gray 1 & None & Cell junction & 56 & 4 & 0.0104 & 0.0806 \\
\hline Light green & Oligodendrocyte & Nerve ensheathment & 474 & 14 & 0.0145 & 0.0998 \\
\hline Seashell & None & Coated vesicle & 313 & 10 & 0.0222 & 0.127 \\
\hline Black & None & Neuropeptide hormone & 1067 & 25 & 0.0226 & 0.127 \\
\hline Tan & Mural Cell & Extracellular matrix & 734 & 18 & 0.033 & 0.171 \\
\hline Blue & Astrocyte & Cadherin & 1508 & 31 & 0.0557 & 0.247 \\
\hline Yellow & Microglia & Immune functions & 1174 & 25 & 0.058 & 0.247 \\
\hline Honey dew & Astrocyte & Muscle contraction & 139 & 5 & 0.0613 & 0.247 \\
\hline Medium blue & None & NAD(P) homeostasis & 233 & 7 & 0.066 & 0.247 \\
\hline Red 4 & Ependymal Cell & Transport & 62 & 3 & 0.0682 & 0.247 \\
\hline Red & Oligodendrocyte & Nerve ensheathment & 1089 & 23 & 0.0717 & 0.247 \\
\hline Gold 3 & Ependymal Cell & Dynein complex & 71 & 3 & 0.0936 & 0.294 \\
\hline Peru & Neuron & Synaptic transmission & 408 & 10 & 0.095 & 0.294 \\
\hline
\end{tabular}

The 20 modules with the strongest Fisher's Exact Test enrichment in AD GWAS genes from the IGAP data set of the 62 multiscale coexpression modules with at least 50 members were considered. P-values were adjusted via the Benjamini-Hochberg method. Size $=$ the number of genes in the module, Shared $=$ the number of overlaps between the IGAP AD GWAS genes and the coexpression modules, GO = Gene Ontology 


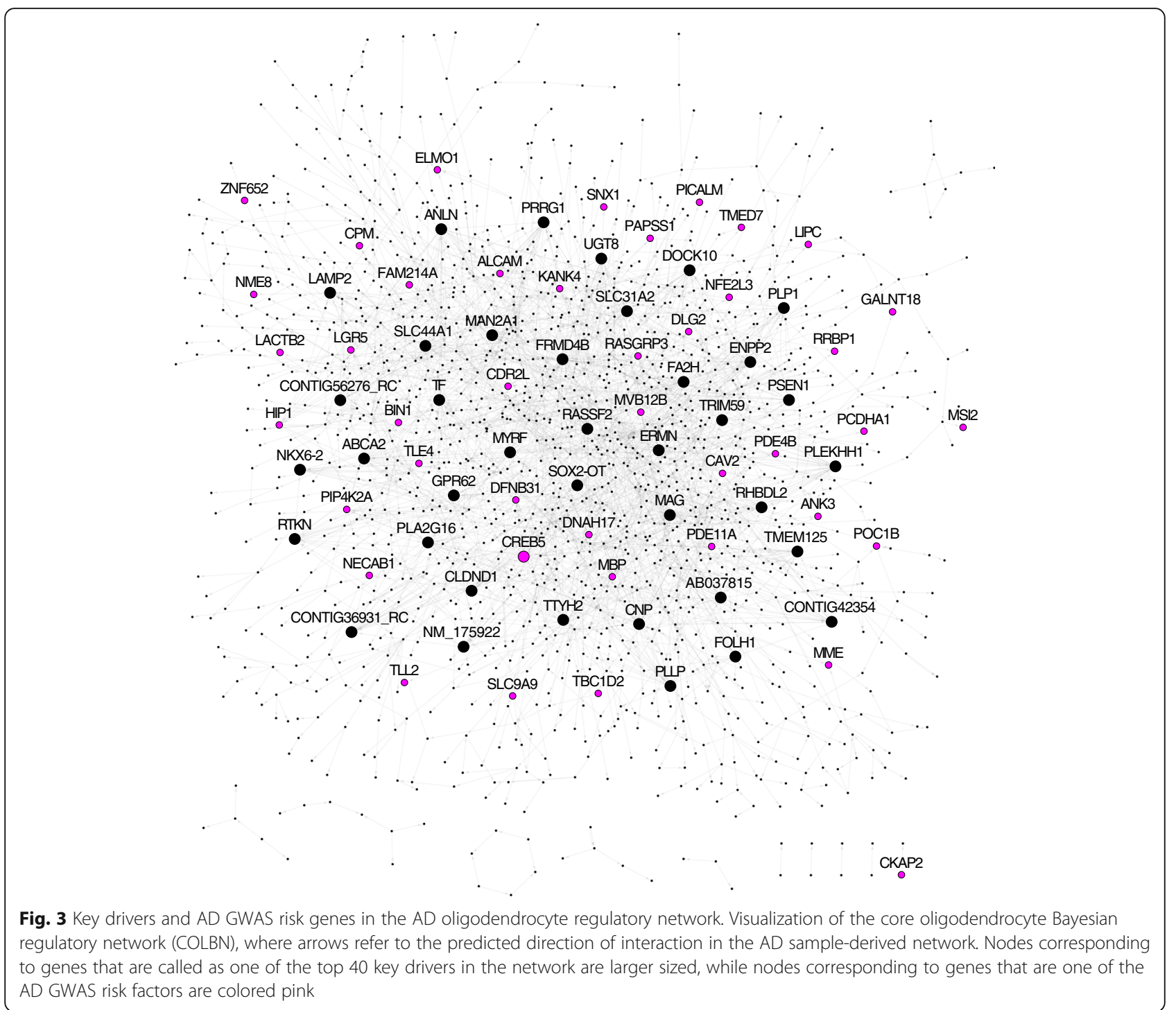

loss of coordination among OL network genes in AD at the protein level. To further explore gene expression changes in this module in $\mathrm{AD}$, we measured differences in protein expression of the module members, identifying 17 proteins up-regulated in $\mathrm{AD}$ and 7 proteins downregulated in $\mathrm{AD}$ at $\mathrm{FDR}<0.3$ and p-value $<0.05$ (Additional file 3). Notably, we found that a BIN1 protein isoform was down-regulated in $\mathrm{AD}(t=-2.4, p=0.019$, FDR $=0.19)$, as well as an MBP protein isoform $(t=-2.3$, $p=0.023$, FDR $=0.19$ ). Therefore, we found that there are both variable changes in expression levels for individual proteins as well as a loss of overall coordination of $\mathrm{OL}$ network protein expression in AD.

\section{Construction and validation of an oligodendrocyte gene regulatory network in $A D$}

We next sought to predict the gene-gene regulatory relationships among the COLGS genes in the RNA expression data, which profiles a wider set of genes than the proteomics data. Specifically, we constructed a Bayesian gene regulatory network for each of the three OL-enriched co-expression modules we identified by integrating RNA expression and genotype data from autopsied brain samples of persons with AD. As detailed in our previous studies [33, 34], Bayesian networks are a type of probabilistic causal network, providing a natural framework for integrating highly dissimilar genetic and gene expression data to predict regulatory relationships. We then combined the three OL Bayesian networks by a set union of directed links, leading to a more robust core oligodendrocyte-enriched Bayesian network (COLBN), and performed key driver analysis on COLBN to identify master regulatory $\mathrm{OL}$ genes in the context of $\mathrm{AD}$ (Fig. 1b; Table 3).

To interrogate the topology of the COLBN as well as how the dysregulation of COLBN key drivers could 
Table 2 The members of the core oligodendrocyte gene set (COLGS) that are identified as significant $(p<0.05)$ AD GWAS hits in the IGAP data set

\begin{tabular}{|c|c|c|c|}
\hline Gene & Chromosome & Top SNP & Top SNP P-value \\
\hline BIN1 & 2 & rs35114168 & $1.05 e-25$ \\
\hline PICALM & 11 & rs639012 & $4.87 \mathrm{e}-19$ \\
\hline NME8 & 7 & rs2060712 & $6.30 \mathrm{e}-07$ \\
\hline SNX1 & 15 & rs138194169 & $2.72 \mathrm{e}-06$ \\
\hline CPM & 12 & rs10878881 & $1.48 \mathrm{e}-05$ \\
\hline DLG2 & 11 & rs422267 & $2.09 \mathrm{e}-05$ \\
\hline RASGRP3 & 2 & rs10200743 & $2.76 \mathrm{e}-05$ \\
\hline GALNT18 & 11 & rs11021857 & $4.511 \mathrm{e}-05$ \\
\hline DNAH17 & 17 & rs117779187 & $7.04 \mathrm{e}-05$ \\
\hline LIPC & 15 & rs17269397 & $8.32 \mathrm{e}-05$ \\
\hline ZNF652 & 17 & rs12948660 & 0.000119 \\
\hline MVB12B & 9 & rs 887656 & 0.000145 \\
\hline CAV2 & 7 & rs75396674 & 0.000157 \\
\hline CREB5 & 7 & rs42711 & 0.000158 \\
\hline NFE2L3 & 7 & rs73281529 & 0.000224 \\
\hline CDR2L & 17 & rs117639581 & 0.000299 \\
\hline PIP4K2A & 10 & rs11013051 & 0.000390 \\
\hline TLL2 & 10 & rs11594430 & 0.000542 \\
\hline RRBP1 & 20 & rs6080757 & 0.000873 \\
\hline KANK4 & 1 & rs114648128 & 0.00118 \\
\hline SLC9A9 & 3 & rs10804689 & 0.00141 \\
\hline HIP1 & 7 & rs10259351 & 0.00165 \\
\hline CKAP2 & 13 & rs58655347 & 0.00168 \\
\hline TLE4 & 9 & rs62569297 & 0.00172 \\
\hline NECAB1 & 8 & rs7003020 & 0.00194 \\
\hline TBC1D2 & 9 & rs73488713 & 0.00222 \\
\hline LGR5 & 12 & rs75928881 & 0.00278 \\
\hline PDE4B & 1 & rs12138629 & 0.00374 \\
\hline PDE11A & 2 & rs4893975 & 0.00380 \\
\hline PAPSS1 & 4 & rs62313402 & 0.00387 \\
\hline DFNB31 & 9 & rs10817615 & 0.00450 \\
\hline MBP & 18 & rs8095585 & 0.00484 \\
\hline LACTB2 & 8 & rs10097463 & 0.00545 \\
\hline ALCAM & 3 & rs114219776 & 0.00628 \\
\hline TMED7 & 5 & rs10069695 & 0.00691 \\
\hline CAT & 11 & rs494024 & 0.00849 \\
\hline MSI2 & 17 & rs12450585 & 0.00849 \\
\hline MME & 3 & rs61758192 & 0.00885 \\
\hline POC1B & 12 & rs770369 & 0.0117 \\
\hline PCDHA1 & 5 & rs2879086 & 0.0151 \\
\hline ANK3 & 10 & rs117641222 & 0.0185 \\
\hline FAM214A & 15 & rs8030871 & 0.0241 \\
\hline ELMO1 & 7 & rs1420423 & 0.0333 \\
\hline
\end{tabular}

The $p$-value column shows the smallest $p$-value of any associated SNP for each gene relate to $\mathrm{AD}$, we identified an in vitro experiment that perturbed a key driver gene in the COLBN, MYRF, and examined how the predicted network structures correspond to its identified experimental targets. Specifically, we used data from a previous study that performed transcriptional profiling of cultured mouse OLs with a deletion of the myelination transcription factor Myrf (also known as C11orf9) [45]. The set of genes differentially expressed in the cells with a Myrf deletion compared with the control was significantly enriched in the 5-layer downstream neighborhood of MYRF in the COLBN $(\mathrm{FE}=2.5, p=7.5 \mathrm{e}-33$; Fig. 5a, Fig. 6a-b), thus validating the topology of the subnetwork regulated by MYRF. The validated downstream targets of MYRF include PLD1, which encodes a protein that regulates the shuttling of $A P P$ and is associated with $A P P$ in AD brains [46, 47], as well as APLP1, which encodes a protein that has been shown to accumulate within neuritic plaques [48].

Next, we validated the network structure of COLBN in vivo using knockout mouse models of three of the top 40 key drivers in COLBN, Ugt8, Cnp, and Plp1, each of which have been found to cause axon pathology without substantial myelin structural alterations [21, 23, 49]. We performed RNAseq (GEO: GSE80437) on tissue samples of postnatal day 20 mice from the frontal cortex (FC) and cerebellum $(\mathrm{CBM})$ in these three mouse models to determine their KO DEG gene signatures at FDR $<0.3$ (Additional files 4 and 5, Additional file 1: Figure S2). We profiled RNA from the FC and CBM because these two regions were also profiled in the human $\mathrm{AD}$ postmortem brain tissue study, from which the COLBN was generated. We selected this time point because we wanted to focus on gene changes that occurred prior to the development of axonal pathology and therefore more directly would allow us to determine gene changes characteristic of the prodromic stage of the disease.We identified no DEGs for $\triangle C n p$ in the CBM and $\triangle P l p 1$ in the $\mathrm{FC}$, while we found that all of the other DEG signatures were significantly enriched in the downstream neighborhoods of their corresponding driver genes (Fig. 6c-d). UGT8 encodes an enzyme that transfers galactose to ceramide to generate galactosylceramide, which makes up approximately one-fourth of myelin lipid dry mass [50]. UGT8's 5-layer neighborhood is most enriched for the Ugt8 $\mathrm{KO}$ signature in the CBM $(\mathrm{FE}=2.1, p=2.4 \mathrm{e}-9)$. One validated downstream target of UGT8 is LIPA, which encodes a lysosomal cholesterol-metabolizing enzyme associated with genetic polymorphisms that affect plasma 24S-hydroxycholesterol/cholesterol levels in AD patients [51] (Fig. 5d). The key driver CNP encodes a protein that plays a role in OL process outgrowth and promoting axon survival [23, 52]. CNP's 5-layer neighborhood is significantly enriched for the Cnp KO signature in the $\mathrm{FC}(\mathrm{FE}=1.7, p=6.4 \mathrm{e}-6)$. One of the 

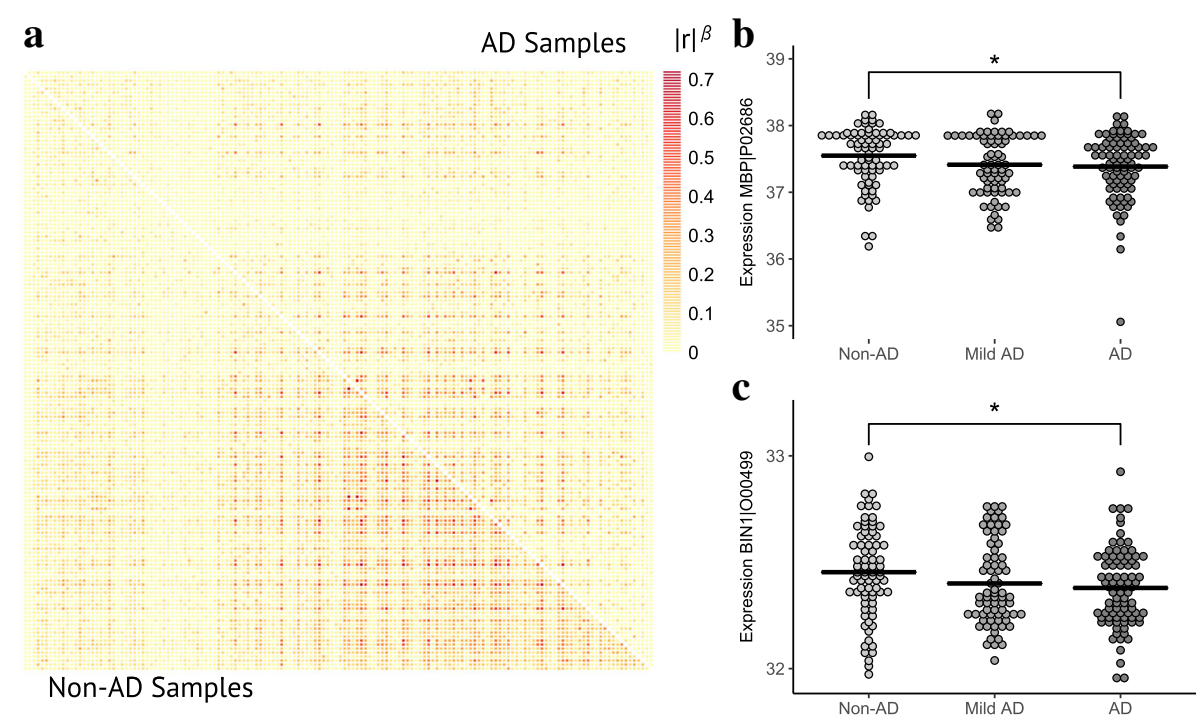

Fig. 4 An oligodendrocyte-enriched protein coexpression module is dysregulated in AD. a Heatmap of transformed correlations in non-AD samples (Braak $<=2$; lower left) and AD samples (Braak > = 5; upper right) in the OL-enriched module consisting of 150 proteins. The transformation consists of taking the absolute value of Pearson correlation coefficients raised to the power of $\beta$, i.e., the soft-thresholding power coefficient of 3 used in coexpression network construction. b, $\mathbf{c}$ Expression levels for MBP (b) and BIN1 (c) in samples classified as non-AD (Braak <=2), mild AD (Braak 3-4), and AD samples (Braak $>=5)$. Significance assessed using Student's t-tests $\left(^{*}=p\right.$-value $\left.<0.05\right)$

validated downstream targets of CNP is SEC14L5, which has been previously found to be down-regulated in CA1 in AD [53] (Fig. 5c). Finally, the key driver PLP1 encodes a protein that is the most abundant protein in CNS myelin sheaths [54], regulates OPC process outgrowth [55], and promotes axonal integrity [56]. PLP1's 5-layer neighborhood is significantly enriched for the Plp1 KO signature in the CBM $(\mathrm{FE}=2.0, p=1.2 \mathrm{e}-4)$. A validated downstream target of Plp1 is Fgf1 (Fig. 5b), which encodes a protein that has been found to stimulate neuronal growth and promote remyelination [57] and has been found to have increased levels in the CSF in AD [58].

Overall, as with the in vitro perturbation data, the in vivo perturbation experiments strongly support the network structure of COLBN and pinpoint specific downstream targets to explain how dysregulation of the key drivers may help mediate AD pathology.

\section{Perturbations of key OL network drivers in mice mimic aspects of dysregulation in human AD brain samples}

Since the key drivers of COLBN are predicted to orchestrate the expression of a network with a strong genetic association with $\mathrm{AD}$, we hypothesized that the $\mathrm{KO}$ signatures of COLBN key drivers in vivo would mimic their gene expression dysregulation in human $\mathrm{AD}$ brains. In order to test this hypothesis, we performed gene ontology analysis on DEG signatures from postmortem brain tissue from both key driver $\mathrm{KO}$ mice and patients with AD. The DEG signatures in AD were derived based on samples from the PFC in the Harvard Brain Tissue Resource Center cohort [26] and samples from the hippocampus (HIPP) in the University of Kentucky Brain Bank cohort [40], because these regions are among those with the strongest AD pathology. Overall, the enrichment of DEGs from the human AD cases in these gene compartments show several similar dysregulation patterns as that seen in the key driver knockouts (Fig. 7a). For example, we identified a strong enrichment for genes in the gene ontology (GO) category "mitochondrial protein complex" in the down-regulated $\Delta C n p$ signature ( $\mathrm{FE}=10.6, p=8.2 \mathrm{e}-22)$ and the down-regulated AD HIPP signature $(\mathrm{FE}=6.7, p=7.5 \mathrm{e}-11)$. We next found that the down-regulated $\triangle C n p$ and AD HIPP signatures intersected along with the mitochondrial gene set substantially more than expected due to chance ( $\mathrm{FE}=34, p=2.1 \mathrm{e}-9$; Fig. $7 \mathrm{~b})$, suggesting that the actual genes dysregulated in the mitochondria are similar between $C n p$-KO mice and in the hippocampus of AD patients. For example, COX6A1, a mitochondrialassociated gene in which mutations are causative of peripheral neuropathy [59], was found to be downregulated in both $\mathrm{Cnp}$-KO mice and in the hippocampus of $\mathrm{AD}$ patients. We also identified a strong enrichment for genes in the GO category "ribosome" in the downregulated $\Delta C n p$ signature $(\mathrm{FE}=4.8, p=3 \mathrm{e}-11)$, the down-regulated $\triangle P l p 1$ signature $(\mathrm{FE}=8.1, p=4 \mathrm{e}-18)$, and the down-regulated AD PFC signature $(\mathrm{FE}=3.0$, $p=0.002$ ). We identified a significant overlap of all three of these down-regulated signatures and the ribosomal 
Table 3 Of the 40 top-ranked key drivers from the core oligodendrocyte-enriched Bayesian network (COLBN), 4 have a type of perturbation signature that we used to validate the network, either in vitro or in vivo

\begin{tabular}{|c|c|c|c|c|c|c|}
\hline Gene Symbol & Major Annotated Roles of Gene Product & Myelin & OL Exosome & Lipid-Binding & AD Risk & Perturbation \\
\hline ERMN & Myelination & Yes & & & & \\
\hline UGT8 & Galactocerebroside production & & & Yes & & In vivo; this study \\
\hline CNP & Myelination; Axon interaction & Yes & Yes & & & In vivo; this study \\
\hline ENPP2 & LPA production & & & & & \\
\hline FRMD4B & $?$ & & & & & \\
\hline PLEKHH1 & ? & & & & & \\
\hline SLC44A1 & Choline transporter & Yes & & & & \\
\hline TRIM59 & $?$ & & & & & \\
\hline PLLP & Myelination & Yes & & Yes & & \\
\hline PRRG1 & $?$ & & & & & \\
\hline SOX2-OT & IncRNA & & & & & \\
\hline CONTIG36931_RC & $?$ & & & & & \\
\hline CLDND1 & $?$ & & & & & \\
\hline ANLN & Actin cytoskeleton & Yes & & & & \\
\hline TTYH2 & Chloride channel & & & & & \\
\hline MYRF & OL differentiation & & & & & In vitro; [49] \\
\hline $\mathrm{FA} 2 \mathrm{H}$ & Ceramide hydroxylation & & & Yes & & \\
\hline CARNS1 & Carnosine production & & & & & \\
\hline RNLS & Alpha-NAD(P)H oxidase & & & & & \\
\hline RASSF2 & Apoptosis & & & & & \\
\hline PRR18 & $?$ & & & & & \\
\hline RTKN & Rho pathway & & & & & \\
\hline DOCK10 & Rho pathway & & & & & \\
\hline LPAR1 & LPA receptor & Yes & & Yes & & \\
\hline MAG & Myelination & Yes & & & & \\
\hline TF & Iron transport & & & & & \\
\hline TMEM125 & $?$ & & & & & \\
\hline PLP1 & Myelination; Axon interaction & Yes & Yes & Yes & & In vivo; this study \\
\hline RHBDL2 & Protease activity & & & & & \\
\hline NKX6-2 & OL differentiation & & & & & \\
\hline FOLH1 & Folate hydrolase & Yes & & & & \\
\hline PSEN1 & Protease activity & & & & Yes & \\
\hline MAN2A1 & Glycosylation & & & & & \\
\hline PLA2G16 & Phospholipase & & & Yes & & \\
\hline CONTIG56276_RC & $?$ & & & & & \\
\hline ABCA2 & Sterol transport & & & & Yes & \\
\hline CREB5 & $?$ & & & & Yes & \\
\hline GPR62 & $?$ & & & & & \\
\hline SLC31A2 & Copper transport & & & & & \\
\hline LAMP2 & Glycosylation & & & & & \\
\hline
\end{tabular}

The Major Annotated Roles of Gene Product column is based on a literature review for the major known role(s) of that gene's product in oligodendrocytes, for which a question mark indicates that no major role is known, to the best of our knowledge. The Myelin column indicates whether or not that gene encodes a protein found in in the myelin proteome [43], the OL Exosome column indicates whether or not that gene encodes a protein found in the OL exosome proteome [97], and the lipid-binding column indicates whether or not that gene encodes a protein found in the set of lipid-binding proteins [98]. The AD risk indicates whether a variant associated with the gene has been previously associated with AD risk, and the Perturbation column indicates whether there is a perturbation signature that we used to corroborate the downstream neighborhood topology for that key driver 

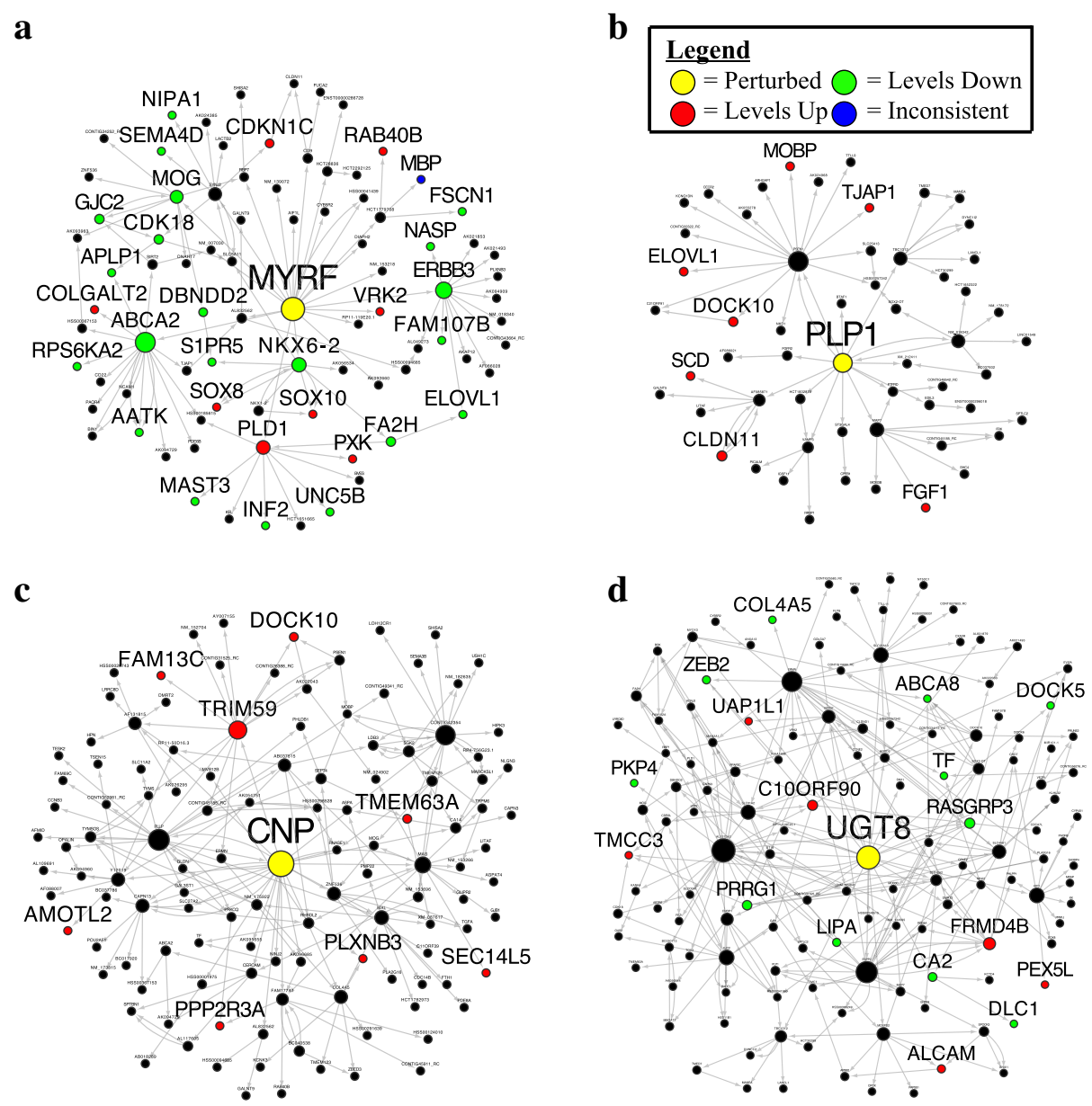

Fig. 5 In vitro and in vivo perturbations of key driver genes in the AD myelin/oligodendrocyte networks validated a number of predicted downstream targets. In these network plots, arrows refer to the predicted direction of interaction in the AD sample-derived core oligodendrocyte Bayesian regulatory network (COLBN). The presence of multiple arrows between two genes is because COLBN was constructed by a union of directed links of three networks from three brain regions. In each plot, the perturbed (i.e., knocked-down or knocked-out) gene is colored yellow, the genes significantly down-regulated in the samples with the driver perturbed are colored green, the genes up-regulated are colored red, and the genes with inconsistent expression changes (i.e., multiple probes corresponding to the same gene show opposite directions of changes in expression) are colored blue. The size of the node is proportional to the number of downstream nodes in the subnetwork. a Validation of the two-layer subnetwork regulated by MYRF using the differentially expressed genes (FDR $<0.3, p<0.05$ ) derived from a Myrf knockout experiment in cultured mouse oligodendrocytes. $\mathbf{b}, \mathbf{c}, \mathbf{d}$ Validation of the two-layer subnetworks regulated by $P L P 1, C N P$, and UGT8 using the differentially expressed gene signatures (FDR $<0.3, p<0.05$ ) from the RNAseq data derived from our knockout experiments in mice

gene set $(\mathrm{FE}=76, p=0.013$; Fig. 7c), which has limited power due to the small size of the overall ribosomal gene set. Since the Cnp and Plp1 knockout RNAseq profiling occurred prior to the typical age of onset of axon degeneration in these mice, the mitochondrial and ribosomal gene set dysregulation seen is suggestive of "presymptomatic" pathways that precede subsequent axonal and neuronal degeneration.

Finally, we also detected that there was a significant enrichment for genes in myelin sheath GO category in the up-regulated $\Delta P l p 1$ signature $(\mathrm{FE}=4.3, \mathrm{p}=3 \mathrm{e}-8)$, the down-regulated $\triangle C n p$ signature $(\mathrm{FE}=2.5$, $\mathrm{p}=0.002)$, and the down-regulated AD HIPP signature $(\mathrm{FE}=5.2, \mathrm{p}=2 \mathrm{e}-9)$. However, the myelin sheath GO signature only contains 161 genes, which makes overlap analysis difficult. In order to use a more well-powered gene set, we utilized a larger set of 1778 genes that have been previously reported to be present in the myelin proteome [43]. In this gene set, we found a strong enrichment for the intersection of genes in the myelin proteome with down-regulated genes in Cnp-KO mice and human $\mathrm{AD}$ hippocampus $(\mathrm{FE}=6.0, \mathrm{p}=2.1 \mathrm{e}-8$; Fig. 7d). This shared set of down-regulated myelin genes includes $C D K 5$, which encodes an enzyme whose activity is associated with tau pathology [60] and is essential for myelination [61]. Both Cnp-KO mice and patients with $\mathrm{AD}$ undergo axon damage in the absence dramatic ultrastructural changes in myelin structure [62], and our data 
$\mathbf{a}$

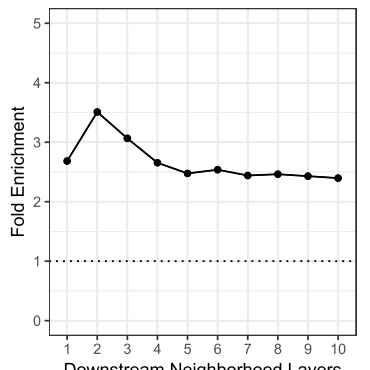

C

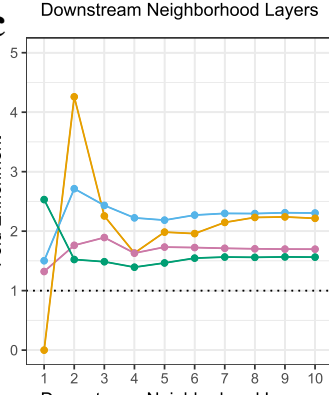

b

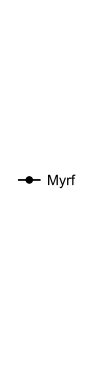

d

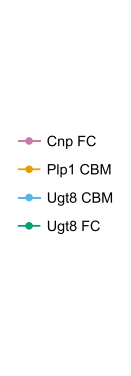

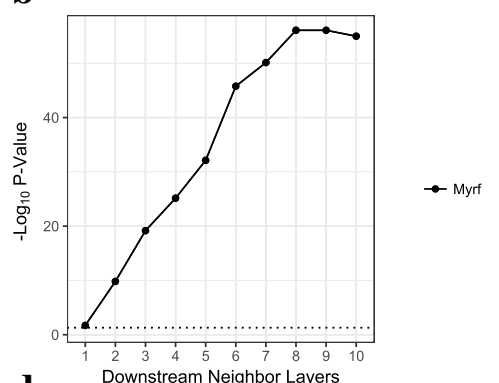

d

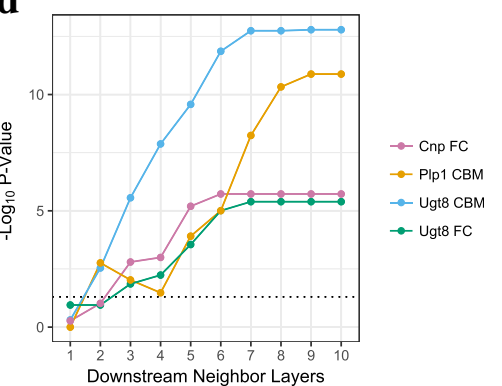

Fig. 6 Gene signatures from in vitro and in vivo perturbations of key driver genes in the AD myelin/oligodendrocyte network are significantly enriched in the predicted subnetworks regulated by the driver genes. $\mathbf{a}$, b Fold-enrichment (a) and BH-adjusted - $\log _{10}$ enrichment $p$-values (b) for the overlap between the Myrf in vitro perturbation signature and each n-layer network neighborhood regulated by MYRF in the core oligodendrocyte Bayesian regulatory network (COLBN). c, d Fold-enrichment (c) and - $\log _{10}$ enrichment p-values (d) for the overlap between each in vivo perturbation signature and each n-layer network neighborhood regulated by the corresponding driver gene. The result was based on the in vivo knockout differentially expressed gene signatures

experiments for Cnp, Plp1, and Ugt8 from the cerebellum (CBM) and/or the frontal cortex (FC)

shows that both conditions share a down-regulation of myelin-associated genes that may be associated with dysmyelination [22] and subsequent axon damage.

In order to validate the decreased expression of key myelin and mitochondrial genes in Cnp-KO mice, we measured the protein expression of BIN1 and GOT2 in Cnp-KO mice compared to WT mice. BIN1 is primarily expressed in mature OLs and white matter in $\mathrm{AD}$ patients [63]. Interestingly, the longer, central nervous system (CNS)-specific isoform of Bin1 has decreased expression levels in AD, although overall Bin1 transcript levels show increased expression [64]. This may reflect a proliferation of monocyte lineage cells in $\mathrm{AD}$ and a concomitant decrease in expression of Bin1 in other cell types, including OLs. BIN1 protein expression has been found to decrease in the myelin proteome of Cnp-KO mice compared to WT mice, but not in Plp-KO, Mag$\mathrm{KO}$, or Sept8-KO mice [65]. Consistent with this previous data, we found a significant down-regulation of BIN1 expression in the corpus callosum in Cnp-KO mice compared to WT mice $(p=0.0041$ and $p=0.0007$, Fig. 8a-b). We selected to profile the corpus callosum because it is an OL- and myelin-rich tissue, and therefore we reasoned that protein expression in this region more accurately would reflect the effect of $\mathrm{Cnp}$-KO on OLs protein expression. No changes in the subcellular distribution of BIN1 were detected in Cnp-KO mice, which was primarily expressed in the cytoplasm of cells that were also stained by antibodies specific for the nuclear pan-OL lineage marker OLIG2 (Fig. 8c-e). Next, we measured the protein expression of GOT2, which is a mitochondrial protein that has been shown to be down-regulated in many AD gene expression studies [66], and has down-regulated transcript levels in Cnp$\mathrm{KO}$ mice in our RNAseq expression profiles. Consistent with this data, we found a down-regulation of GOT2 protein levels in Cnp-KO mice ( $p=0.0332$; Fig. 8a-b). Although GOT2 has been identified in the myelin proteome, we found that it was primarily co-expressed with neurons (Fig. 8f-h), suggesting that the loss of Cnp expression may also affect mitochondrial gene expression within neurons. Taken together, these results validate that $\mathrm{Cnp}-\mathrm{KO}$ mice have gene dysregulation in key myelin and mitochondrial proteins that is similar to that seen in $\mathrm{AD}$ brain samples.

\section{Discussion}

In this study, we employed an unbiased systems biology approach to characterize OL-enriched and $\mathrm{AD}$ associated co-expression and regulatory molecular networks. We derived a core OL-enriched gene set (COLGS) that was highly enriched in AD GWAS genes. We found that this set of genes strongly overlapped with the corresponding genes from a protein co-expression 

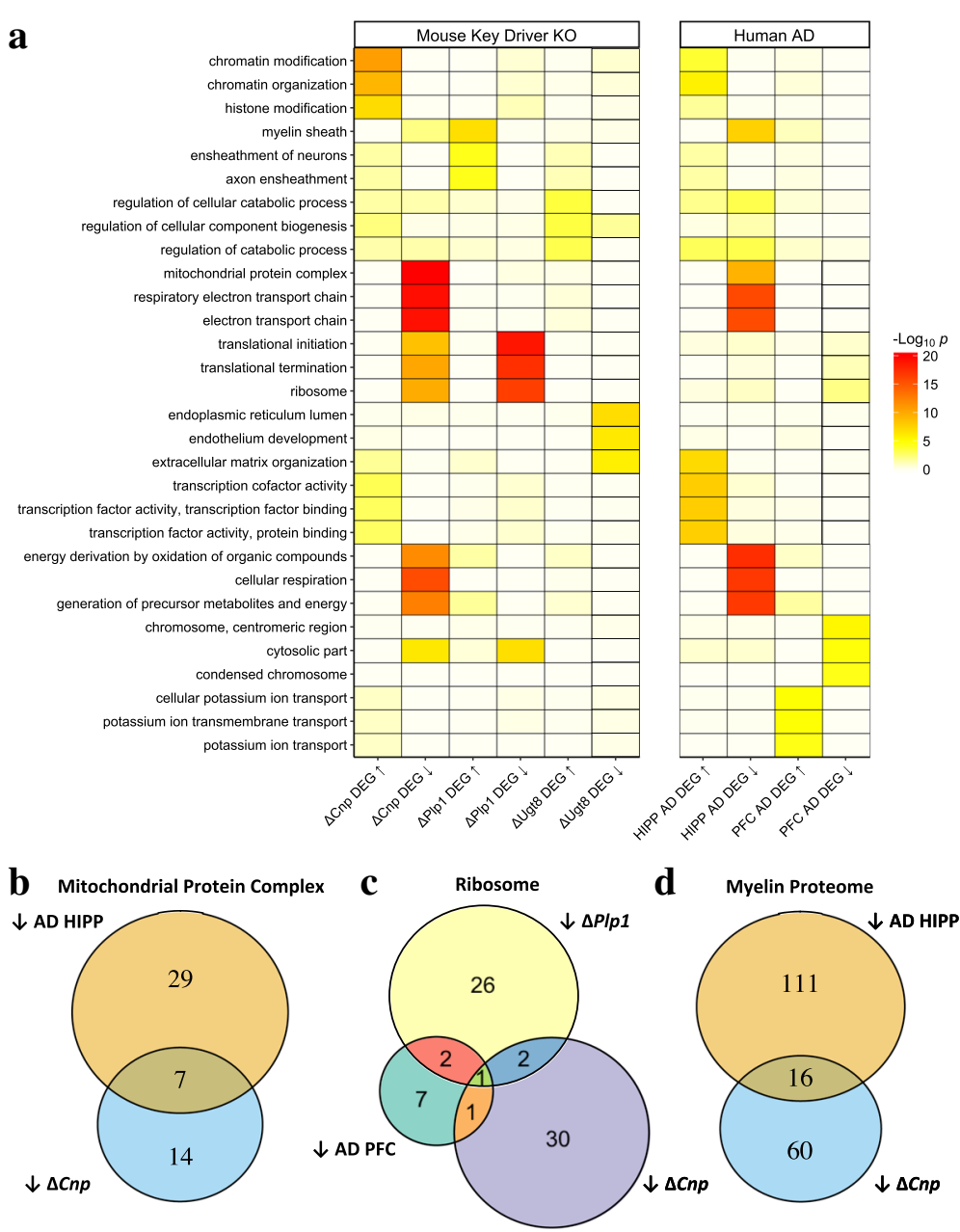

Fig. 7 Perturbation of oligodendrocyte network key drivers in mice recapitulates key gene expression changes in human AD brain samples. a A heatmap of the - $\log _{10}$ gene ontology $(\mathrm{GO})$ enrichment p-values of core oligodendrocyte Bayesian regulatory network key driver knockout differentially expressed gene (DEG) signatures (left panel) and AD DEG signatures from the hippocampus and prefrontal cortex (right panel). The top 3 GO terms with between 100 and 800 gene symbols most enriched in each of the DEG signatures are shown. The $p$-values for each tested signature were adjusted using the Benjamini-Hochberg method. $\mathbf{b}, \mathbf{c}, \mathbf{d}$ Venn diagrams showing the intersections of genes encoding proteins associated with the GO terms "mitochondrial protein complex" (b), "ribosome" (c), and genes in the myelin proteome (d) with genes downregulated in various DEG signatures are shown

module, which we found to be highly dysregulated in AD. We next constructed a core OL Bayesian regulatory network (COLBN) to dissect the causal relationships among the genes in COLGS. By employing a series of in vitro and in vivo perturbations of key driver genes in COLBN, we validated the predicted network structures in COLBN. We further showed that the knockouts of key drivers of COLBN in mice mimic the dysregulation of OL-associated compartments of genes in human postmortem AD brains. In particular, our data revealed a surprisingly strong, convergent gene expression effect of the knockouts $C n p$ and Plp1 on organelle-associated gene expression pathways, specifically in genes annotated for mitochondrial and ribosome functions. These organelles have also been reported to be dysregulated in axons in AD brains [17, 67-69], suggesting that altered
OL-axon communication may lead to dysregulated expression of ribosomal and mitochondrial genes and possibly play a role in contributing to $\mathrm{AD}$ axonal pathology. It is difficult to study prodromal changes in late-onset $\mathrm{AD}$ brains, because we are not able to determine a priori the individuals who would progress to AD. However, in mice with well-defined ablation of myelin genes also detected as key drivers of human gene network in AD, it is possible to define alterations that occur in $\mathrm{OL}$ and that precede frank neurodegeneration. For this reason the detection of similar gene changes in brain tissue samples of Cnp-KO and Plp1-KO mice prior to the development of any axonal pathology [22, 24], allowed us to infer that the dysregulated expression of similar genes in murine samples and in human AD brains is suggestive of similar events occurring during the early part of the 


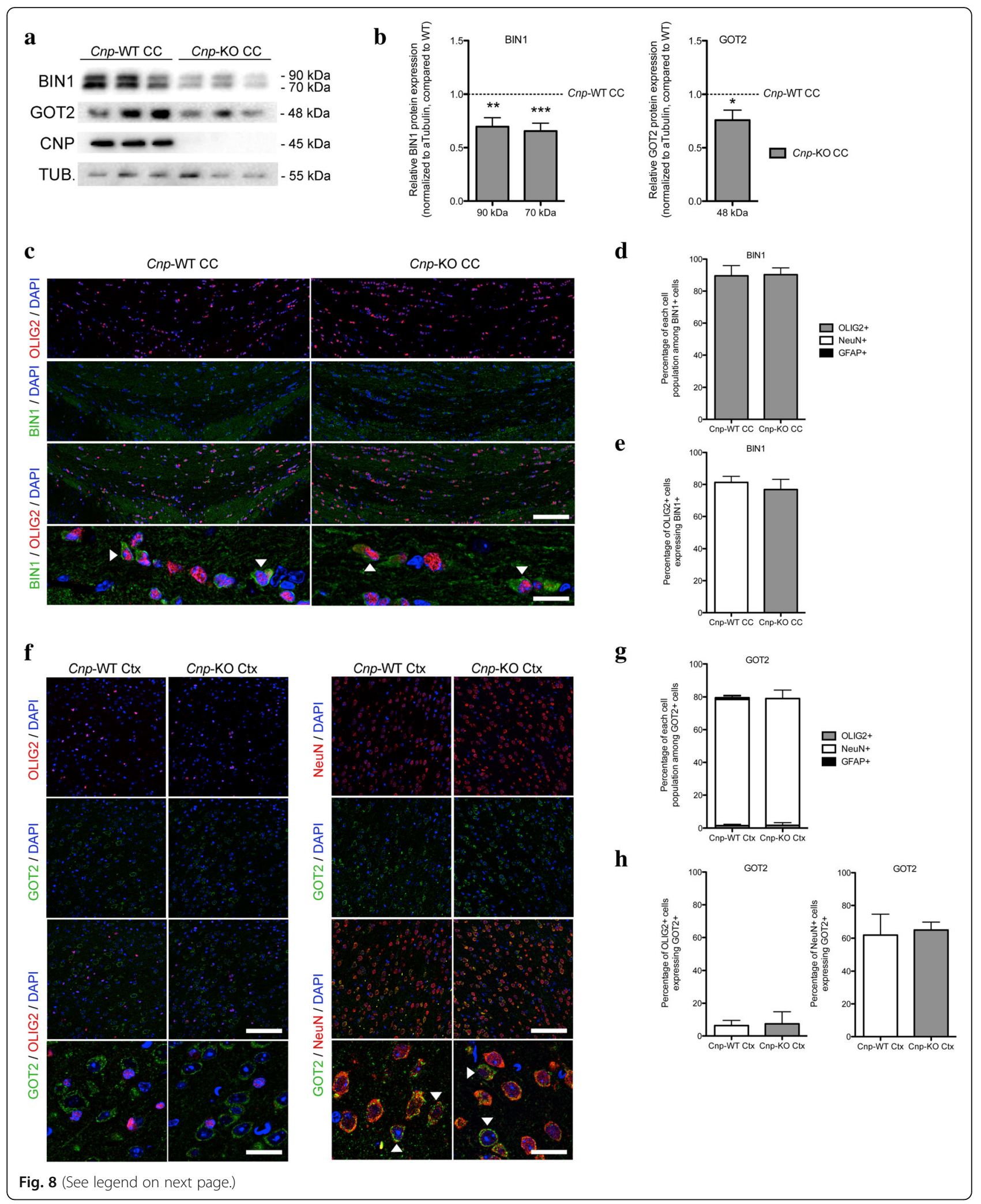




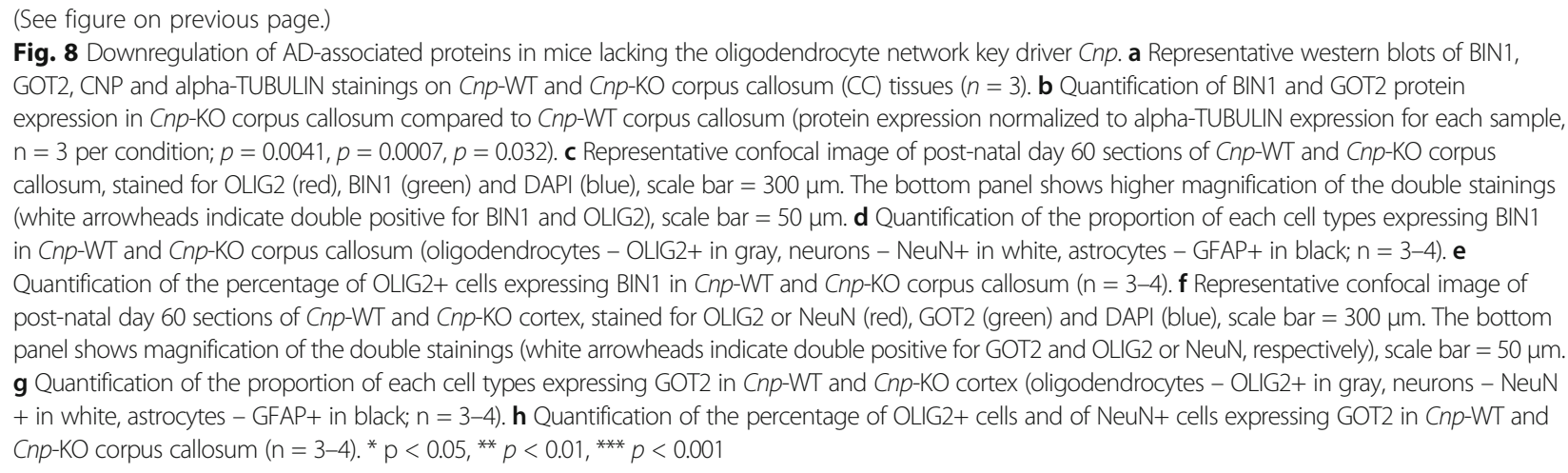

pathological cascade. Overall, this study improves our understanding of the molecular underpinnings of myelination and OLs in AD by identifying biologically relevant pathways, dissecting the causal relationships among the OL- and myelin-related genes, and implicating key driver genes in $\mathrm{AD}$ pathogenesis.

At the individual gene level, many of the genes in COLGS have been described as genetic risk factors associated with late-onset $\mathrm{AD}$, including BIN1 [28], PICALM [28], NME8 [28], UNC5C [30], and PSEN [27]. Notably, BIN1 is the nearest protein-coding gene to the SNP with the second-strongest GWAS signal for $A D$, following APOE [28]. Histologically, BIN1 is primarily found in the brain at the nodes of Ranvier, consistent with its high RNA expression in OLs and its presence in the myelin proteome [43, 70, 71]. In COLBN, BIN1 is downstream of $A B C A 2$, a cholesterol transporter that has been associated with the risk of $\mathrm{AD}$ in many study populations $[28,72-$ 75]. Much of the literature about the role of BIN1 in AD has focused on its roles in neurons and microglia [76], but our data, in addition to another recent study [63], suggest that its role in OLs should be explored further. In addition to genetic risk factors, our AD OL network also contains many genes encoding proteins that have been associated with $\mathrm{AD}$ pathophysiology (e.g., via $\mathrm{A} \beta$ production) including PSEN1 [77], BACE1 [77], PLD1 [46, 78], and APLP1 [79]. Consistent with the important role of $B A C E 1$ in OLs suggested by our network, $B A C E 1$ has been shown to play a key role in myelination [80, 81]. The role of $B A C E 1$ in OLs is of high relevance to $A D$, as mutations in the $B A C E 1$-cleaving region of APP have been associated with a decreased risk of $\mathrm{AD}$ [82], and $\beta$-secretase inhibitors intended to treat $\mathrm{AD}$ may have side-effects of myelin defects [83]. A focus on the interaction targets of both PSEN1 and BACE1 within OLs using regulatory networks may be a fruitful avenue to identify treatment modalities that decrease deleterious $A \beta$ production without causing off-target effects.

At the gene set level, our enrichment analysis of the AD co-expression modules shows that the three modules significantly enriched for $\mathrm{AD}$ risk genes are associated with three different cell types, i.e., microglia, OLs, and neurons (Table 1). Note that gene modules were identified based on the correlation between gene expression profiles in postmortem human $\mathrm{AD}$ brains, and they don't necessarily correspond to any particular known cell types or biological processes due to interactions among cell types and biological processes. Therefore, we denote the co-expression modules by randomly selected color names in addition to their most enriched gene ontology term, to emphasize their multifaceted and highly context-dependent functions. The top ranked module was enriched for immune (microglia/macrophage) genes, consistent with recent reports that immune cells and in particular innate immunity plays a critical role in promoting $\mathrm{AD}[76,84-86]$. However, it is imprudent to focus on a single cell type and ignore the interactions with other cells. For example, TREM2, an established AD risk factor that is primarily expressed in immune cells $[87,88]$, is also the causative gene of Nasu-Hakola disease, an earlyonset subcortical dementia that presents with white matter demyelination [89]. Mice lacking Trem 2 have been shown to have delayed myelin debris clearance, which may lead to increased microglia activation and thus demyelination and neuronal death [90]. The dysregulation of myelin proteome genes that we observed in $\mathrm{AD}$ may contribute to pathologic inflammation, by increasing the available lipid pool for scavenging by microglia, which can activate microglia into a pro-inflammatory state [91, 92]. Further investigation of cell type interactions in $\mathrm{AD}$ via network biology is a promising approach in addressing the underlying causes of AD.

Existing mouse models of $A D$ tend to focus on $A \beta$ and/or neuronal deficits in AD. For example, several mouse models of $\mathrm{AD}$ express genes with familial $\mathrm{AD}$ causative mutations under the Thy1 promoter [93-95], which is a neuronal marker and will serve to restrict the pathologic changes to neurons. However, the data presented in this study and others suggest that the dysregulation of other cell types, including OLs, may play a role in $\mathrm{AD}$. This opens up a need for mouse models of $\mathrm{AD}$ that can recapitulate the OL- and myelin-associated 
dysregulation in $\mathrm{AD}$. In this study, we found that a mouse knockout model of one of the key drivers in the OL network, Cnp, demonstrates a strikingly similar myelin and mitochondrial dysregulation pattern as is seen in brain samples of patients with $\mathrm{AD}$. Notably, we did expression profiling prior to the onset of axon degeneration in $\mathrm{Cnp}$-KO mice [22], to minimize the possibility that the myelin gene expression changes observed would be reactive to as opposed to premonitory for axon damage. Taken together, our data suggest that the Cnp-KO mice may be a good model of the OL network gene dysregulation and dysmyelination that occurs in the brains of patients with $\mathrm{AD}$. Therefore, therapeutic agents that are able to mitigate and/or prevent the dysmyelination and axon degeneration seen in $\mathrm{Cnp}$-KO mice are worthwhile of investigation as potential therapeutic agents for ameliorating cognitive deficits in patients with $\mathrm{AD}$.

In this study, we focused on the molecular networks in $\mathrm{AD}$ in a brain cell type, OLs, which have not been widely studied in AD. Our network modeling approach uncovered a network of OL-associated genes that is enriched for $\mathrm{AD}$ GWAS genes, pathways through which dysregulation of this OL network may promote AD pathology, and key driver genes that orchestrate these pathways. Further work on our model for the role of OLs in AD may help to address why aging is the major risk factor for $\mathrm{AD}$, since myelin maintenance and plasticity are known to become progressively less robust in normal aging $[62,96]$. In particular, preventing or reversing the dysregulation of key $\mathrm{OL}$ driver genes such as CNP and downstream targets such as $B I N 1$ deserve further research as interventions to help to alleviate the progression of cognitive deficits in $\mathrm{AD}$.

\section{Conclusions}

This study systematically identifies and validates a comprehensive molecular blueprint of OLs in the context of $\mathrm{AD}$. Our gene network analysis of large-scale genetic and genomic data from $\mathrm{AD}$ brains reveals that $\mathrm{OL} /$ myelin-enriched subnetworks in multiple brain regions are strongly associated with clinical and neuropathologic traits in AD. These $\mathrm{OL} /$ myelin-enriched subnetworks harbor not only $\mathrm{A} \beta$ production-related genes, but also several genes involved in myelin biology. Our network analysis further identifies key causal regulators of the OL/myelin-enriched networks, including UGT8, CNP, MYRF, and PLP1. These predicted network structures can be validated by gene perturbation signatures of these drivers. Mice with genetic ablations of Cnp mimicked components of organelle and myelin sheath gene expression dysregulation seen in brain samples from patients with $\mathrm{AD}$, including decreased protein expression of BIN1 and GOT2. Overall, our network models of OLs in $\mathrm{AD}$ and the comprehensive validation experiments reveal details of the molecular mechanisms of $\mathrm{OL}$ dysregulation in $\mathrm{AD}$ and thus pave a way for the development of novel AD therapies.

\section{Additional files}

\begin{abstract}
Additional file 1: Supplementary Experimental Procedures. Figure S1. The topological overlap matrix plot of the protein co-expression network constructed from the proteomics data from the autopsied brains in the MSBB cohort, along with the dendrogram showing the tree cutting process used to define modules (above). Figure S2. Confirmation that the key driver knockouts abrogate gene expression of the key driver in the RNA-seq experiments. For each of the key driver knockouts whose genome-wide gene expression was profiled in this study using RNA-seq, we plotted the $\log _{10}$ counts overlapping that gene in both the wildtype (WT) and knockout (KO) samples. Notably, one of the matched samples from Cnp was detected as an outlier in both the CBM and FC brain regions (red), due to suspected mislabeling. These samples were removed prior to downstream differential expression analysis. (DOCX $161 \mathrm{~kb}$ )
\end{abstract}

Additional file 2: Module membership file for the Mount Sinai Brain Bank (MSBB) proteomic coexpression network. The module label, a randomly chosen color name, is in the 1st column, while the protein name is in the 2 nd column. (TSV $34 \mathrm{~kb}$ )

Additional file 3: Differentially expressed proteins in the MSBB proteomics data set between AD cases and controls in the OL-enriched module (which has been randomly assigned the color name "Yellow"). (TSV $9 \mathrm{~kb}$ )

Additional file 4: Summary of read mapping from the three knockout mouse RNAseq experiments generated by TopHat. (XLSX 52 kb)

Additional files 5: Differentially expressed genes found the mouse knockout RNAseq analyses of Ugt8 in the CBM (Data 1) and FC (Data 2), Cnp in the FC (Data 3), and Plp1 in the CBM (Data 4). For these differential expression analyses, we mapped RNAseq reads using TopHat, converted to count space using HTSeq, used voom to transform the read space data to $\log _{2}$ counts per million, and used limma for differential expression analysis. We also used the Ensembl database to identify the human gene with the highest homology percentage based on protein coding region DNA divergence, and report this homology percentage for each gene. Note that the differential expression signatures of $\mathrm{C} n \mathrm{p}$ in the CBM and PIp 1 in the FC were not found not have any differentially expressed genes at FDR $<0.3$, so they are not included here. (ZIP $358 \mathrm{~kb}$ )

\section{Abbreviations}

AD: Alzheimer's disease; AB: Amyloid beta; CBM: Cerebellum; CNS: Central nervous system; COLBN: Core oligodendrocyte-enriched Bayesian network; COLGS: Core oligodendrocyte gene set; DEG: Differentially expressed gene; eSNPs: Expression single nucleotide polymorphisms; FC: Frontal cortex; FDR: False discovery rate; FE: Fold enrichment; FET: Fisher's exact test; GEO: Gene expression omnibus; GO: Gene ontology; GWAS: Genome-wide association study; HBTRC: Harvard brain tissue resource center; HGNC: Hugo Gene nomenclature committee; HIPP: Hippocampus; IGAP: International genomics of Alzheimer's Project; KO: Knockout; MSBB: Mount Sinai Brain Bank; OL: Oligodendrocyte; PFC: Prefrontal cortex; RIN: RNA integrity number; RNAseq: RNA sequencing; VC: Visual cortex; WGCNA: Weighted gene coexpression network analysis

\section{Acknowledgments}

We would like to thank members of the Zhang and Casaccia labs for many fruitful discussions.

\section{Funding}

This work was supported by the NIH grants R01AG046170, U01AG052411, RF1AG054014, RF1AG057440, R01AG057907, U01Al111598-01, R01NS067550, P50AG025688, U01AG046161, and F30AG052261. R01AG046170 is a component of the AMP-AD Target Discovery and Preclinical Validation Project. We thank the International Genomics of Alzheimer's Project (IGAP) for providing summary results data for these analyses. The investigators within IGAP contributed to the design and implementation of IGAP and/or provided data but did not participate in analysis or writing of this report. IGAP was made possible by the generous participation of the control subjects, the patients, and their families. The i-Select chips was funded by the French National Foundation on Alzheimer's disease and related disorders. EADI was supported by the LABEX (laboratory of excellence program investment for 
the future) DISTALZ grant, Inserm, Institut Pasteur de Lille, Université de Lille 2 and the Lille University Hospital. GERAD was supported by the Medical Research Council (Grant $n^{\circ}$ 503,480), Alzheimer's Research UK (Grant $n^{\circ}$ 503,176), the Wellcome Trust (Grant $n^{\circ}$ 082604/2/07/Z) and German Federal Ministry of Education and Research (BMBF): Competence Network Dementia (CND) grant $n^{\circ} 01 \mathrm{Gl} 0102,01 \mathrm{Gl} 0711,01 \mathrm{Gl}$ 0420. CHARGE was partly supported by the NIH/NIA grant R01 AG033193 and the NIA AG081220 and AGES contract N01-AG-12100, the NHLBI grant R01 HL105756, the Icelandic Heart Association, and the Erasmus Medical Center and Erasmus University. ADGC was supported by the NIH/NIA grants: U01 AG032984, U24 AG021886, U01 AG016976, and the Alzheimer's Association grant ADGC-10-196,728.

\section{Availability of data and materials}

The RNA-sequencing data from the mouse key driver knockout experiments are available at Gene Expression Omnibus (GEO) GSE80437. All other relevant data is described elsewhere and available from the authors upon request.

\section{Authors' contributions}

Conceptualization, ATM, SM, BZ and PC; Methodology, ATM, SM, BZ and PC; Software, ATM, MW, IK, W-MS, XZ, ED, JZ and BZ; Investigation, ATM, SM, BZ and PC; Resources, ATM, SM, BP, JA, K-A N, ED, DD, JL, NS, AL, EE, B.Z and PC; Writing - Original Draft, ATM; Writing - Review \& Editing All Authors; Supervision, $\mathrm{BZ}$ and $\mathrm{PC}$; Funding Acquisition, $\mathrm{BZ}$ and $\mathrm{PC}$. All authors read and approved the final manuscript.

\section{Authors' information}

Not applicable.

\section{Ethics approval}

Use of animals in this research was strictly compliant with the guidelines set forth by the US Public Health Service in their policy on Humane Care and Use of Laboratory Animals, and in the Guide for the Care and Use of Laboratory Animals. All animal procedures received prior approval from the Institutional Animal Care and Use Committee at Icahn School of Medicine at Mount Sinai (IACUC 08-676)

\section{Consent for publication}

Not applicable.

\section{Competing interests}

The authors declare that they have no competing interests.

\section{Publisher's Note}

Springer Nature remains neutral with regard to jurisdictional claims in published maps and institutional affiliations.

\section{Author details}

1Department of Genetics and Genomic Sciences, Icahn School of Medicine at Mount Sinai, One Gustave L. Levy Place, 1470 Madison Avenue, Room S8-111, New York, NY 10029, USA. ${ }^{2}$ Icahn Institute of Genomics and Multiscale Biology, Icahn School of Medicine at Mount Sinai, One Gustave L. Levy Place, New York, NY 10029, USA. ${ }^{3}$ Medical Scientist Training Program, Icahn School of Medicine at Mount Sinai, One Gustave L. Levy Place, New York, NY 10029, USA. ${ }^{4}$ Fishberg Department of Neuroscience and Friedman Brain Institute, Icahn School of Medicine at Mount Sinai, One Gustave L. Levy Place, New York, NY 10029, USA. ${ }^{5}$ Department of Human Genetics, Emory University School of Medicine, Atlanta, GA 30322, USA. ${ }^{6}$ Department of Biochemistry, Emory University School of Medicine, Atlanta, GA 30322, USA. ${ }^{7}$ Integrated Proteomics Core Facility, Emory University School of Medicine, Atlanta, GA 30322, USA. ${ }^{8}$ Department of Neurology, The University of Chicago Pritzker School of Medicine, 5841 S. Maryland Avenue, Chicago, IL 60637, USA. ${ }^{9}$ Department of Neurology, Emory University School of Medicine, Atlanta, GA 30322, USA. ${ }^{10}$ Center for Neurodegenerative Disease, Emory University School of Medicine, Atlanta, GA 30322, USA. ${ }^{11}$ Department of Psychiatry, Icahn School of Medicine at Mount Sinai, New York, NY 10029, USA. ${ }^{12}$ Mental IIIness Research, Education, and Clinical Center (VISN 3), James J. Peters VA Medical Center, Bronx, NY 10468, USA. ${ }^{13}$ Neuroscience Initiative, The City University of New York, Advanced Science Research Center, 85 St. Nicholas Terrace, New York, NY 10031, USA.
Received: 19 June 2017 Accepted: 17 October 2017

Published online: 06 November 2017

\section{References}

1. Hebert LE, Weuve J, Scherr PA, Evans DA. Alzheimer disease in the United States (2010-2050) estimated using the 2010 census. Neurology. 2013;80:1778-83.

2. Plassman $B L$, Langa $K M$, Fisher $G G$, Heeringa $S G$, Weir DR, Ofstedal MB, Burke JR, Hurd MD, Potter GG, Rodgers WL, et al. Prevalence of dementia in the United States: the aging, demographics, and memory study. Neuroepidemiology. 2007;29:125-32.

3. Jack CR, Wiste HJ, Weigand SD, Knopman DS, Vemuri P, Mielke MM, Lowe $V$ Senjem ML, Gunter JL, Machulda MM, et al. Age, sex, and APOE \&4 effects on memory, brain structure, and $\beta$-Amyloid across the adult life span. JAMA Neurol. 2015;72:511-9.

4. Veeraraghavalu K, Zhang C, Zhang X, Tanzi RE, Sisodia SS. Age-dependent, non-cell-autonomous deposition of amyloid from synthesis of $\beta$-amyloid by cells other than excitatory neurons. J Neurosci. 2014;34:3668-73.

5. Li C, Zhao R, Gao K, Wei Z, Yin MY, Lau LT, Chui D, Hoi Yu AC. Astrocytes: implications for neuroinflammatory pathogenesis of Alzheimer's disease. Curr Alzheimer Res. 2011;8:67-80.

6. Griciuc A, Serrano-Pozo A, Parrado AR, Lesinski AN, Asselin CN, Mullin K, Hooli B, Choi SH, Hyman BT, Tanzi RE. Alzheimer's disease risk gene CD33 inhibits microglial uptake of amyloid beta. Neuron. 2013;78:631-43.

7. Salat DH, Greve DN, Pacheco JL, Quinn BT, Helmer KG, Buckner RL, Fischl B. Regional white matter volume differences in nondemented aging and Alzheimer's disease. Neurolmage. 2009:44:1247-58.

8. Cash DM, Ridgway GR, Liang Y, Ryan NS, Kinnunen KM, Yeatman T, Malone IB, Benzinger TLS, Jack CR, Thompson PM, et al. The pattern of atrophy in familial Alzheimer disease: volumetric MRI results from the DIAN study. Neurology. 2013;81:1425-33.

9. Salat DH, Kaye JA, Janowsky JS. Prefrontal gray and white matter volumes in healthy aging and Alzheimer disease. Arch Neurol. 1999;56:338-44.

10. Hua X, Hibar DP, Lee S, Toga AW, Jack CR, Weiner MW, Thompson PM. Sex and age differences in atrophic rates: an ADNI study with $n=1368 \mathrm{MRI}$ scans. Neurobiol Aging. 2010;31:1463-80.

11. Lee GJ, Lu PH, Hua X, Lee S, Wu S, Nguyen K, Teng E, Leow AD, Jack CR, Toga AW, et al. Depressive symptoms in mild cognitive impairment predict greater atrophy in Alzheimer's disease-related regions. Biol Psychiatry. 2012;71:814-21.

12. Lee GJ, Lu PH, Medina LD, Rodriguez-Agudelo Y, Melchor S, Coppola G, Braskie MN, Hua X, Apostolova LG, Leow AD, et al. Regional brain volume differences in symptomatic and presymptomatic carriers of familial Alzheimer's disease mutations. J Neurol Neurosurg Psychiatry. 2013;84:154-62.

13. Braak H, Braak E. Development of Alzheimer-related neurofibrillary changes in the neocortex inversely recapitulates cortical myelogenesis. Acta Neuropathol. 1996;92:197-201.

14. Braak H, Del Tredici K. The preclinical phase of the pathological process underlying sporadic Alzheimer's disease. Brain. 2015;138((Pt 10)):2814-33.

15. Kim JY, Shen S, Dietz K, He Y, Howell O, Reynolds R, Casaccia P. HDAC1 nuclear export induced by pathological conditions is essential for the onset of axonal damage. Nat Neurosci. 2010;13:180-9.

16. Werner HB, Kuhlmann K, Shen S, Uecker M, Schardt A, Dimova K, Orfaniotou F, Dhaunchak A, Brinkmann BG, Möbius W, et al. Proteolipid protein is required for transport of sirtuin 2 into CNS myelin. J Neurosci. 2007;27:7717-30.

17. Nave K-A. Myelination and the trophic support of long axons. Nat Rev Neurosci. 2010;11:275-83.

18. Nave K-A, Werner HB. Myelination of the nervous system: mechanisms and functions. Annu Rev Cell Dev Biol. 2014;30:503-33.

19. Vossel KA, Zhang K, Brodbeck J, Daub AC, Sharma P, Finkbeiner S, Cui B, Mucke L. Tau reduction prevents Abeta-induced defects in axonal transport. Science (New York, NY). 2010;330:198.

20. Zhang B, Maiti A, Shively S, Lakhani F, McDonald-Jones G, Bruce J, Lee EB, Xie SX, Joyce S, Li C, et al. Microtubule-binding drugs offset tau sequestration by stabilizing microtubules and reversing fast axonal transport deficits in a tauopathy model. Proc Natl Acad Sci U S A. 2005;102:227-31.

21. Coetzee T, Fujita N, Dupree J, Shi R, Blight A, Suzuki K, Popko B. Myelination in the absence of galactocerebroside and sulfatide: normal structure with abnormal function and regional instability. Cell. 1996:86:209-19.

22. Edgar JM, McLaughlin M, Werner HB, McCulloch MC, Barrie JA, Brown A, Faichney AB, Snaidero N, Nave K-A, Griffiths IR. Early ultrastructural defects of axons and axon-glia junctions in mice lacking expression of Cnp1. Glia. 2009;57:1815-24. 
23. Lappe-Siefke C, Goebbels S, Gravel M, Nicksch E, Lee J, Braun PE, Griffiths IR, Nave K-A. Disruption of Cnp1 uncouples oligodendroglial functions in axonal support and myelination. Nat Genet. 2003;33:366-74.

24. Edgar JM, McLaughlin M, Yool D, Zhang SC, Fowler JH, Montague P, Barrie JA, McCulloch MC, Duncan ID, Garbern J, et al. Oligodendroglial modulation of fast axonal transport in a mouse model of hereditary spastic paraplegia. J Cell Biol. 2004;166(1):121-31.

25. Griffiths I, Klugmann M, Anderson T, Yool D, Thomson C, Schwab MH, Schneider A, Zimmermann F, McCulloch M, Nadon N, et al. Axonal swellings and degeneration in mice lacking the major proteolipid of myelin. Science. 1998;280(5369):1610-3.

26. Zhang B, Gaiteri C, Bodea L-G, Wang Z, McElwee J, Podtelezhnikov AA, Zhang C, Xie T, Tran L, Dobrin R, et al. Integrated systems approach identifies genetic nodes and networks in late-onset Alzheimer's disease. Cell. 2013;153:707-20.

27. Cruchaga C, Haller G, Chakraverty S, Mayo K, Vallania FLM, Mitra RD, Faber K, Williamson J, Bird T, Diaz-Arrastia R, et al. Rare variants in APP, PSEN1 and PSEN2 increase risk for AD in late-onset Alzheimer's disease families. PLoS One. 2012;7:e31039.

28. Lambert JC, Ibrahim-Verbaas CA, Harold D, Naj AC, Sims R, Bellenguez C, DeStafano AL, Bis JC, Beecham GW, Grenier-Boley B, et al. Meta-analysis of 74,046 individuals identifies 11 new susceptibility loci for Alzheimer's disease. Nat Genet. 2013:45:1452-8.

29. Ahmed RR, Holler CJ, Webb RL, Li F, Beckett TL, Murphy MP. BACE1 and BACE2 enzymatic activities in Alzheimer's disease. J Neurochem. 2010;112:1045-53.

30. Wetzel-Smith MK, Hunkapiller J, Bhangale TR, Srinivasan K, Maloney JA Atwal JK, Sa SM, Yaylaoglu MB, Foreman O, Ortmann W, et al. A rare mutation in UNC5C predisposes to late-onset Alzheimer's disease and increases neuronal cell death. Nat Med. 2014;20:1452-7.

31. Zhang B, Horvath S. A general framework for weighted gene co-expression network analysis. Stat Appl Genet Mol Biol. 2005;4:Article17.

32. Zhang Y, Chen K, Sloan SA, Bennett ML, Scholze AR, O'Keeffe S, Phatnan HP, Guarnieri P, Caneda C, Ruderisch N, et al. An RNA-sequencing Transcriptome and splicing database of Glia, neurons, and vascular cells of the cerebral cortex. J Neurosci. 2014;34:11929-47.

33. Zhu J, Wiener MC, Zhang C, Fridman A, Minch E, Lum PY, Sachs JR, Schadt EE. Increasing the power to detect causal associations by combining genotypic and expression data in segregating populations. PLoS Comput Biol. 2007;3(4):e69

34. Zhu J, Zhang B, Smith EN, Drees B, Brem RB, Kruglyak L, Bumgarner RE, Schadt EE. Integrating large-scale functional genomic data to dissect the complexity of yeast regulatory networks. Nat Genet. 2008;40:854-61.

35. Wang I-M, Zhang B, Yang X, Zhu J, Stepaniants S, Zhang C, Meng Q, Peters M, $\mathrm{He} Y, \mathrm{Ni}$, et al. Systems Analysis of Eleven Rodent Disease Models Reveals an Inflammatome Signature and Key Drivers. Mol Syst Biol 2012, (in press).

36. Mishra A, Macgregor S. VEGAS2: software for more flexible gene-based testing. Twin Res Hum Genet. 2015;18:86-91.

37. McKenzie AT, Katsyv I, Song WM, Wang M, Zhang B. DGCA: a comprehensive $\mathrm{R}$ package for differential gene correlation analysis. BMC Syst Biol. 2016;10(1):106.

38. Storey J. Qvalue: Q-value estimation for false discovery rate control. 2015.

39. Anders S, Reyes A, Huber W. Detecting differential usage of exons from RNA-seq data. Genome Res. 2012;22:2008-17.

40. Blalock EM, Geddes JW, Chen KC, Porter NM, Markesbery WR, Landfield PW. Incipient Alzheimer's disease: microarray correlation analyses reveal major transcriptional and tumor suppressor responses. Proc Natl Acad Sci U S A. 2004; 101:2173-8

41. Falcon S, Gentleman R. Using GOstats to test gene lists for GO term association. Bioinformatics (Oxford, England). 2007;23:257-8.

42. Wang M, Zhao $Y$, Zhang B. Efficient test and visualization of multi-set intersections. Sci Rep. 2015:5:16923.

43. Dagley LF, White CA, Liao Y, Shi W, Smyth GK, Orian JM, Emili A, Purcell AW. Quantitative proteomic profiling reveals novel region-specific markers in the adult mouse brain. Proteomics. 2014;14:241-61.

44. Miller JA, Oldham MC, Geschwind DH. A systems level analysis of transcriptional changes in Alzheimer's disease and normal aging. J Neurosci. 2008;28:1410-20.

45. Emery B, Agalliu D, Cahoy JD, Watkins TA, Dugas JC, Mulinyawe SB, Ibrahim A, Ligon KL, Rowitch DH, Barres BA. Myelin gene regulatory factor is a critical transcriptional regulator required for CNS Myelination. Cell. 2009;138:172-85.
46. Cai D, Zhong M, Wang R, Netzer WJ, Shields D, Zheng H, Sisodia SS, Foster DA, Gorelick FS, Xu H, et al. Phospholipase D1 corrects impaired betaAPP trafficking and neurite outgrowth in familial Alzheimer's disease-linked presenilin-1 mutant neurons. Proc Natl Acad Sci U S A. 2006;103:1936-40.

47. Jin J-K, Ahn B-H, Na Y-J, Kim J-I, Kim Y-S, Choi E-K, Ko Y-G, Chung KC, Kozlowski PB, Min DS. Phospholipase D1 is associated with amyloid precursor protein in Alzheimer's disease. Neurobiol Aging. 2007;28:1015-27.

48. Bayer TA, Paliga K, Weggen S, Wiestler OD, Beyreuther K, Multhaup G. Amyloid precursor-like protein 1 accumulates in neuritic plaques in Alzheimer's disease. Acta Neuropathol. 1997;94:519-24.

49. Klugmann M, Schwab MH, Pühlhofer A, Schneider A, Zimmermann F, Griffiths IR, Nave KA. Assembly of CNS myelin in the absence of proteolipid protein. Neuron. 1997;18:59-70.

50. Morell P, Quarles RH. Characteristic Composition of Myelin. Philadelphia: Lippincott-Raven; 1999.

51. von Trotha KT, Heun R, Schmitz S, Lutjohann D, Maier W, Kolsch H. Influence of lysosomal acid lipase polymorphisms on chromosome 10 on the risk of Alzheimer's disease and cholesterol metabolism. Neurosci Lett. 2006;402(3):262-6

52. Lee J. Process outgrowth in oligodendrocytes is mediated by CNP, a novel microtubule assembly myelin protein. J Cell Biol. 2005;170:661-73.

53. Miller JA, Woltjer RL, Goodenbour JM, Horvath S, Geschwind DH. Genes and pathways underlying regional and cell type changes in Alzheimer's disease. Genome Med. 2013;5(5):48.

54. de Monasterio-Schrader P, Jahn O, Tenzer S, Wichert SP, Patzig J, Werner HB. Systematic approaches to central nervous system myelin. Cell Mol Life Sci. 2012;69(17):2879-94.

55. Harlow DE, Saul KE, Culp CM, Vesely EM, Macklin WB. Expression of proteolipid protein gene in spinal cord stem cells and early oligodendrocyte progenitor cells is dispensable for normal cell migration and myelination. J Neurosci. 2014;34:1333-43.

56. Garbern JY, Yool DA, Moore GJ, Wilds IB, Faulk MW, Klugmann M, Nave K-A, Sistermans EA, van der Knaap MS, Bird TD, et al. Patients lacking the major CNS myelin protein, proteolipid protein 1, develop length-dependent axonal degeneration in the absence of demyelination and inflammation. Brain. 2002:125:551-61.

57. Mohan H, Friese A, Albrecht S, Krumbholz M, Elliott CL, Arthur A, Menon R, Farina C, Junker A, Stadelmann C, et al. Transcript profiling of different types of multiple sclerosis lesions yields FGF1 as a promoter of remyelination. Acta Neuropathol Commun. 2014;2:168.

58. Mashayekhi F, Hadavi M, Vaziri HR, Naji M. Increased acidic fibroblast growth factor concentrations in the serum and cerebrospinal fluid of patients with Alzheimer's disease. J Clin Neurosci. 2010;17(3):357-9.

59. Tamiya G, Makino S, Hayashi M, Abe A, Numakura C, Ueki M, Tanaka A, Ito C, Toshimori K, Ogawa N, et al. A mutation of COX6A1 causes a recessive axonal or mixed form of Charcot-Marie-tooth disease. Am J Hum Genet. 2014:95:294-300.

60. Piedrahita D, Hernández I, López-Tobón A, Fedorov D, Obara B, Manjunath BS, Boudreau RL, Davidson B, Laferla F, Gallego-Gómez JC, et al. Silencing of CDK5 reduces neurofibrillary tangles in transgenic alzheimer's mice. J Neurosci. 2010;30:13966-76.

61. Yang Y, Wang H, Zhang J, Luo F, Herrup K, Bibb JA, Lu R, Miller RH. Cyclin dependent kinase 5 is required for the normal development of oligodendrocytes and myelin formation. Dev Biol. 2013;378:94-106.

62. Bartzokis G. Alzheimer's disease as homeostatic responses to age-related myelin breakdown. Neurobiol Aging. 2011;32:1341-71.

63. De Rossi P, Buggia-Prevot V, Clayton BL, Vasquez JB, van Sanford C, Andrew RJ, Lesnick R, Botte A, Deyts C, Salem S, et al. Predominant expression of Alzheimer's disease-associated BIN1 in mature oligodendrocytes and localization to white matter tracts. Mol Neurodegener. 2016;11(1):59.

64. Holler CJ, Davis PR, Beckett TL, Platt TL, Webb RL, Head E, Murphy MP. Bridging integrator 1 (BIN1) protein expression increases in the Alzheimer's disease brain and correlates with neurofibrillary tangle pathology. J Alzheimers Dis. 2014:42(4):1221-7.

65. Patzig J, Erwig MS, Tenzer S, Kusch K, Dibaj P, Mobius W, Goebbels S, Schaeren-Wiemers N, Nave KA, Werner HB. Septin/anillin filaments scaffold central nervous system myelin to accelerate nerve conduction. elife. 2016;5: e17119.

66. Puthiyedth N, Riveros C, Berretta R, Moscato P. Identification of differentially expressed genes through integrated study of Alzheimer's disease affected brain regions. PLoS One. 2016;11(4):e0152342. 
67. Calkins MJ, Manczak M, Mao P, Shirendeb U, Reddy PH. Impaired mitochondrial biogenesis, defective axonal transport of mitochondria, abnormal mitochondrial dynamics and synaptic degeneration in a mouse model of Alzheimer's disease. Hum Mol Genet. 2011:20:4515-29.

68. lijima-Ando K, Sekiya M, Maruko-Otake A, Ohtake Y, Suzuki E, Lu B, lijima KM. Loss of axonal mitochondria promotes tau-mediated neurodegeneration and Alzheimer's disease-related tau phosphorylation via PAR-1. PLoS Genet. 2012;8:e1002918.

69. González C, Couve A. The axonal endoplasmic reticulum and protein trafficking: cellular bootlegging south of the soma. Semin Cell Dev Biol. 2014;27:23-31.

70. Butler MH, David C, Ochoa GC, Freyberg Z, Daniell L, Grabs D, Cremona O, De Camilli P. Amphiphysin II (SH3P9; BIN1), a member of the amphiphysin/ Rvs family, is concentrated in the cortical cytomatrix of axon initial segments and nodes of ranvier in brain and around T tubules in skeletal muscle. J Cell Biol. 1997;137:1355-67.

71. Zhang Y, Sloan Steven A, Clarke Laura E, Caneda C, Plaza Colton A, Blumenthal Paul D, Vogel H, Steinberg Gary K, Edwards Michael SB, Li G, et al. Purification and characterization of progenitor and mature human Astrocytes reveals transcriptional and functional differences with mouse. Neuron. 2015:89:37-53.

72. Macé $S$, Cousin E, Ricard S, Génin E, Spanakis E, Lafargue-Soubigou C, Génin $B$, Fournel $R$, Roche $S$, Haussy $G$, et al. $A B C A 2$ is a strong genetic risk factor for early-onset Alzheimer's disease. Neurobiol Dis. 2005;18:119-25.

73. Wollmer MA, Kapaki E, Hersberger M, Muntwyler J, Brunner F, Tsolaki M, Akatsu H, Kosaka K, Michikawa M, Molyva D, et al. Ethnicity-dependent genetic association of ABCA2 with sporadic Alzheimer's disease. Am J Med Genet B Neuropsychiatr Genet. 2006;141B:534-6.

74. Xu X, Wang Y, Wang L, Liao Q, Chang L, Xu L, Huang Y, Ye H, Xu L, Chen C, et al. Meta-analyses of 8 polymorphisms associated with the risk of the Alzheimer's disease. PLoS One. 2013;8:e73129.

75. Minster RL, DeKosky ST, Kamboh MI. No association of DAPK1 and ABCA2 SNPS on chromosome 9 with Alzheimer's disease. Neurobiol Aging. 2009;30:1890-1.

76. Karch CM, Goate AM. Alzheimer's disease risk genes and mechanisms of disease pathogenesis. Biol Psychiatry. 2015;77:43-51.

77. Karran E, Mercken M, De Strooper B. The amyloid cascade hypothesis for Alzheimer's disease: an appraisal for the development of therapeutics. Nat Rev Drug Discov. 2011;10(9):698-712.

78. Liu Y, Zhang Y-W, Wang X, Zhang H, You X, Liao F-F, Xu H. Intracellular trafficking of presenilin 1 is regulated by beta-amyloid precursor protein and phospholipase D1. J Biol Chem. 2009;284:12145-52.

79. Zhou F, van Laar T, Huang H, Zhang L. APP and APLP1 are degraded through autophagy in response to proteasome inhibition in neuronal cells. Protein \& cell. 2011;2:377-83.

80. Treiber $\mathrm{H}$, Hagemeyer $\mathrm{N}$, Ehrenreich $\mathrm{H}$, Simons M. BACE1 in central nervous system myelination revisited. Mol Psychiatry. 2012;17:237-9.

81. Hu X, Hicks CW, He W, Wong P, Macklin WB, Trapp BD, Yan R. Bace1 modulates myelination in the central and peripheral nervous system. Nat Neurosci. 2006;9:1520-5.

82. Jonsson T, Atwal JK, Steinberg S, Snaedal J, Jonsson PV, Bjornsson S, Stefansson H, Sulem P, Gudbjartsson D, Maloney J, et al. A mutation in APP protects against Alzheimer's disease and age-related cognitive decline. Nature. 2012;488:96-9.

83. Willem M, Garratt AN, Novak B, Citron M, Kaufmann S, Rittger A, DeStrooper B, Saftig P, Birchmeier C, Haass C. Control of peripheral nerve myelination by the beta-secretase BACE1. Science (New York, NY). 2006;314:664-6.

84. Miller JA, Woltjer RL, Goodenbour JM, Horvath S, Geschwind DH. Genes and pathways underlying regional and cell type changes in Alzheimer's disease. Genome Med. 2013;5:48.

85. Jones L, Lambert J-C, Wang L-S, Choi S-H, Harold D, Vedernikov A, Escott-Price V, Stone T, Richards A, Bellenguez C, et al. Convergent genetic and expression data implicate immunity in Alzheimer's disease. Alzheimers Dement. 2015;11(6):658-71.

86. Seyfried NT, Dammer EB, Swarup V, Nandakumar D, Duong DM, Yin L, Deng Q, Nguyen T, Hales CM, Wingo T, et al. A multi-network approach identifies protein-specific co-expression in asymptomatic and symptomatic Alzheimer's disease. Cell Syst. 2017:4(1):60-72 e64.

87. Jin SC, Benitez BA, Karch CM, Cooper B, Skorupa T, Carrell D, Norton JB, Hsu S, Harari O, Cai Y, et al. Coding variants in TREM2 increase risk for Alzheimer's disease. Hum Mol Genet. 2014;23:5838-46.

88. Guerreiro R, Wojtas A, Bras J, Carrasquillo M, Rogaeva E, Majounie E, Cruchaga C, Sassi C, Kauwe JSK, Younkin S, et al. TREM2 variants in Alzheimer's disease. N Engl J Med. 2013;368:117-27.
89. Paloneva J, Manninen T, Christman G, Hovanes K, Mandelin J, Adolfsson R, Bianchin M, Bird T, Miranda R, Salmaggi A, et al. Mutations in two genes encoding different subunits of a receptor signaling complex result in an identical disease phenotype. Am J Hum Genet. 2002;71:656-62.

90. Poliani PL, Wang Y, Fontana E, Robinette ML, Yamanishi Y, Gilfillan S, Colonna M. TREM2 sustains microglial expansion during aging and response to demyelination. J Clin Invest. 2015;125:2161-70.

91. Painter MM, Atagi Y, Liu CC, Rademakers R, Xu H, Fryer JD, Bu G. TREM2 in CNS homeostasis and neurodegenerative disease. Mol Neurodegener. 2015;10:43.

92. Cherry JD, Olschowka JA, O'Banion MK. Neuroinflammation and M2 microglia: the good, the bad, and the inflamed. J Neuroinflammation. 2014;11:98.

93. Oakley H, Cole SL, Logan S, Maus E, Shao P, Craft J, Guillozet-Bongaarts A, Ohno M, Disterhoft J, Van Eldik L, et al. Intraneuronal beta-amyloid aggregates, neurodegeneration, and neuron loss in transgenic mice with five familial Alzheimer's disease mutations: potential factors in amyloid plaque formation. J Neurosci. 2006;26(40):10129-40.

94. Radde R, Bolmont T, Kaeser SA, Coomaraswamy J, Lindau D, Stoltze L, Calhoun ME, Jaggi F, Wolburg H, Gengler S, et al. Abeta42-driven cerebral amyloidosis in transgenic mice reveals early and robust pathology. EMBO Rep. 2006;7(9):940-6.

95. Sturchler-Pierrat C, Abramowski D, Duke M, Wiederhold KH, Mistl C, Rothacher S, Ledermann B, Burki K, Frey P, Paganetti PA, et al. Two amyloid precursor protein transgenic mouse models with Alzheimer disease-like pathology. Proc Natl Acad Sci U S A. 1997:94(24):13287-92.

96. Krestinina O, Azarashvili T, Baburina Y, Galvita A, Grachev D, Stricker R, Reiser $\mathrm{G}$. In aging, the vulnerability of rat brain mitochondria is enhanced due to reduced level of 2',3'-cyclic nucleotide-3'-phosphodiesterase (CNP) and subsequently increased permeability transition in brain mitochondria in old animals. Neurochem Int. 2015;80:41-50.

97. Krämer-Albers E-M, Bretz N, Tenzer S, Winterstein C, Möbius W, Berger H, Nave K-A, Schild H, Trotter J. Oligodendrocytes secrete exosomes containing major myelin and stress-protective proteins: Trophic support for axons? Proteomics Clin Appl. 2007;1:1446-61.

98. Subramaniam S, Fahy E, Gupta S, Sud M, Byrnes RW, Cotter D, Dinasarapu AR, Maurya MR. Bioinformatics and systems biology of the lipidome. Chem Rev. 2011;111:6452-90

\section{Submit your next manuscript to BioMed Central and we will help you at every step:}

- We accept pre-submission inquiries

- Our selector tool helps you to find the most relevant journal

- We provide round the clock customer support

- Convenient online submission

- Thorough peer review

- Inclusion in PubMed and all major indexing services

- Maximum visibility for your research

Submit your manuscript at www.biomedcentral.com/submit

) Biomed Central 